\title{
A Comprehensive Study of Large Negative Dispersion and Highly Nonlinear Perforated Core PCF: Theoretical Insight
}

\section{Anurag Upadhyay}

Rajkiya Engineering College Azamgarh

\section{Shivam Singh}

Motilal Nehru National Institute of Technology

\section{Divya Sharma}

Thapar Institute of Engineering and Technology

Sofyan A Taya ( $\nabla$ staya@iugaza.edu.ps )

Islamic University of Gaza https://orcid.org/0000-0001-5060-2534

\section{Research Article}

Keywords: Photonic Crystal Fiber (PCF), Hole Packing Density (HPD), Birefringence, Nonlinear Coefficient, Dispersion, Numerical Aperture (NA)

Posted Date: May 3rd, 2021

DOl: https://doi.org/10.21203/rs.3.rs-227813/v1

License: (c) (i) This work is licensed under a Creative Commons Attribution 4.0 International License. Read Full License 


\title{
A Comprehensive Study of Large Negative Dispersion and Highly Nonlinear Perforated Core PCF: Theoretical Insight
}

\author{
Anurag Upadhyay ${ }^{1}$, Shivam Singh ${ }^{2}$, Divya Sharma ${ }^{3}$, Sofyan A. Taya ${ }^{4 *}$
}

1. Department of Applied Science \& Humanities, Rajkiya Engineering College, Azamgarh, U. P., India. Email: anurag.upadhyay009@gmail.com

2. Department of Electronics \& Communication Engineering, Motilal Nehru National Institute of Technology Allahabad, Prayagraj, U. P., India. Email: shivams20@gmail.com

3. Department of Electronics \& Communication Engineering, Thapar Institute of Engineering and Technology, Patiala, Punjab, India. Email: divya.fgiet@gmail.com

4. Department of Physics, Islamic University of Gaza, Gaza Strip, Palestine. Email: staya@iugaza.edu.ps

*Corresponding Author

Sofyan A. Taya

Department of Physics, Islamic University of Gaza, Gaza Strip, Palestine.

Email: staya@iugaza.edu.ps

\begin{abstract}
:
This manuscript deals with a novel photonic crystal fiber (PCF) in which PCF's cladding region bears the air holes of square shape organized in a circular manner. The fiber core is perforated with four circular air-filled holes to instate high nonlinearity and large negative dispersion. The numerical analysis of the designed model is supported by the finite element method (FEM) based COMSOL Multiphysics tool. The optical properties of the propounded PCF like nonlinearity, dispersion, effective area and propagation loss have been observed by altering its geometrical dimensions, especially the diameter of four air holes introduced in the fiber core. Simulation outcome verifies a very high nonlinear coefficient value of $300 \mathrm{~W}^{-1} \mathrm{Km}^{-1}$ which is the highest ever achieved value without using any nonlinear materials or liquids in the author's best knowledge. In parallel, the chromatic dispersion is also found negative and reached to the maximum value of $-1689 \mathrm{ps} / \mathrm{nm} / \mathrm{km}$. Besides, the other essential optical parameters such as birefringence, numerical aperture, and propagation loss were also measured as $2.40 \times 10^{-3}, 0.59$, and $4.12 \times 10^{-11} \mathrm{~dB} / \mathrm{m}$ along with an extremely high core power fraction of $99.98 \%$. Hence, the propounded PCF is suitable for residual dispersion compensation, supercontinuum generation, solitons generation, polarization sustaining devices as well for high bitrate transmission.
\end{abstract}

Keywords: Photonic Crystal Fiber (PCF); Hole Packing Density (HPD); Birefringence; Nonlinear Coefficient; Dispersion; Numerical Aperture (NA)

\section{Introduction:}

Nowadays PCF is a hot research topic as it finds applications in numerous fields such as biomedical imaging, supercontinuum generation and in sensing enactment [1]. PCF realization obviated the structural and background material limitations [2]. Based on PCF's operation mechanism, it can be classified into two categories that are index guiding (IG) and photonic bandgap (PBG). With the aid of the periodic cladding arrangement, light can be confined in 
the core region of IG-PCF via modified total internal reflection (TIR). While in PBG, light can be confined in the core of lower RI compared to cladding via bandgap effect. PCF exhibits various optical properties contrary to conventional optical fiber such as high birefringence, low confinement loss, high nonlinearity, low waveguide dispersion etc. [3-4]. PCF consists of many tiny periodic holes in its cladding region which runs throughout the fiber length. PCF shows interesting attribute that optical properties can be amended by changing its structural parameters without change in its background material. PCF can be applicable for dispersion compensating fiber in the field of high-speed communication as the desirable dispersion properties can be obtained with the variation in structure design [5]. Reeves et al. reported in his research article that very low dispersion variation of $\pm 0.24 \mathrm{ps} / \mathrm{nm} / \mathrm{km}$ with low fiber loss of $0.08 \mathrm{~dB} / \mathrm{m}$ could be obtained by proper designing of PCF [6]. Reeves in another literature found that low loss and flattened dispersion could be observed with several airhole rings in the cladding of fiber [7]. In the same way, Saitoh et al. demonstrated that dispersion can also be controlled by the core airhole defects in a PCF [8]. Marcos et al. in his article obtained a very high average negative dispersion for microstructure PCF [9]. In 2015, a research article admitted that PCF with square shaped air holes in the core and cladding region can achieve large negative dispersion of $-780 \mathrm{ps} / \mathrm{nm} / \mathrm{km}$ [10]. In 2019, Das et al. showed that liquid infiltration in the core hole of PCF displayed large negative dispersion of $-1600 \mathrm{ps} / \mathrm{nm} / \mathrm{km}$ along with shift in the zero-dispersion wavelength [11]. In the same year, G. D. Krishna showed that desirable dispersion and confinement loss could be achieved with airhole defects in the core of PCF [12]. While in 2020, Anurag et al. achieved dispersion of $-810 \mathrm{ps} / \mathrm{nm} / \mathrm{km}$ for PCF with square air holes in the core as well as in the cladding [13]. Birefringence and nonlinearity are other important optical properties of PCF which can be amended by modifying its core and cladding air holes. Bo et al. in his research article proposed a hybrid PCF and achieved birefringence of $1.56 \times 10^{-3}$ at the wavelength $1.20 \mu \mathrm{m}$ [14]. Whereas, Yu et al. showed birefringence and nonlinearity of $0.92 \times 10^{-3}$ and $20 \mathrm{~W}^{-1} \mathrm{Km}^{-1}$ at $1.33 \mu \mathrm{m}$, respectively for the elliptical rhombus air core PCF [15]. Arif et al. proposed simple hexagonal lattice PCF and obtained high birefringence and nonlinearity equal to $1.83 \times 10^{-3}$ and $20.04 \mathrm{~W}^{-1} \mathrm{Km}^{-1}[16]$. Hexagonal lattice PCF with elliptical core holes has been realized for liquid sensing and achieved birefringence of $1.95 \times 10^{-3}$ at $1.20 \mu \mathrm{m}$ [17]. High birefringence of $1.45 \times 10^{-3}$ with a low loss figure has been reported for H-PCF by Cheng et al. in his research article [18]. While Ahmed et al. recommended an octagonal PCF with the square core for liquid sensing with high nonlinearity of $3.26 \mathrm{~W}^{-1} \mathrm{Km}^{-1}$ and low confinement loss at $1.33 \mu \mathrm{m}$ operating wavelength [19]. 
Hao et al. in his research showed birefringence of $2 \times 10^{-3}$ with negative dispersion of -20 $\mathrm{ps} / \mathrm{nm} / \mathrm{km}$ for the PCF with elliptical lattice pattern of circular air holes [20].

In this manuscript a novel five circular rings of square air holes are proposed with circular airhole core defects. Four airhole core defects are placed at vertices of a square as shown in Fig. 1. The entire structure is conceptualized based on FEM. Simulation results show that large negative dispersion of $-1689 \mathrm{ps} / \mathrm{nm} / \mathrm{km}$ is achieved for the propounded structure. Moreover, high birefringence of $2.40 \times 10^{-3}$ and high nonlinearity of $300 \mathrm{~W}^{-1} \mathrm{Km}^{-1}$ with very low confinement loss of $10^{-11}$ are resulted in the recommended structure. Apart from this, some other essential optical parameters like core power fraction (CPF), group birefringence, numerical aperture (NA), effective V-parameter and beat length are also investigated for the proposed structure. Fabrication feasibility is considered while choosing dimensions and shape of propounded PCF and hole packing density (HPD) has been deliberately chosen well within practical fabrication limit.

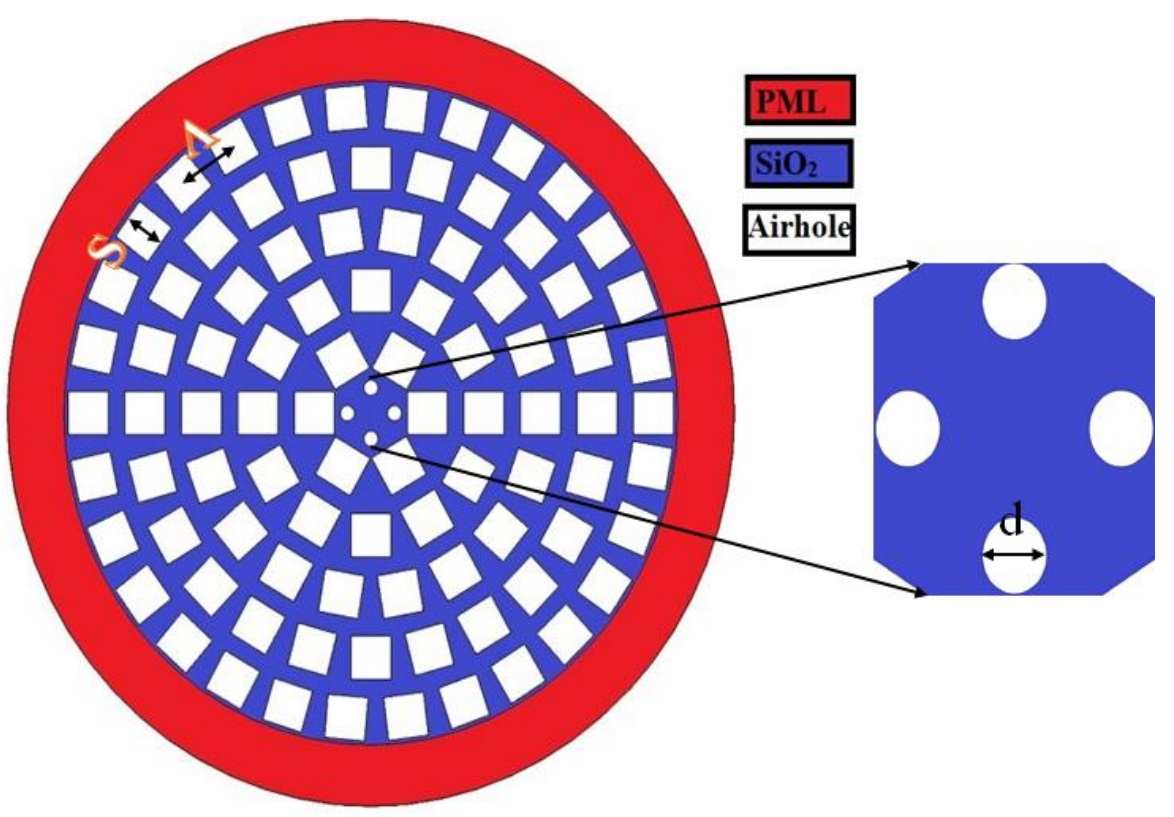

Fig. 1: 2D schematic of the square airhole cladding proposed PCF with enlarge view of the porous core section having circular air holes.

\section{Design of Structure:}

The proposed PCF cross section is shown in Fig. 1 with an enlarged view of its core. The cladding of the recommended PCF is consisted with periodic arrangement of square air holes. Five circular rings of square air holes are preferred in the cladding for concentrating the mode light within the core of PCF. Such an annular ring PCF shows the behavior of step index fiber [21]. Here, we have preferred square airhole instead of circular air holes because square air 
holes provide larger HPD (i.e.S/ $\Lambda$ ) as compared to circular air holes for the same width of square airhole and diameter of circular airhole [13, 22].

The radius of square airhole rings is given below:

$\mathrm{R}=n_{R} \times \Lambda$

Where $n_{R}$ denotes the number of rings ( 1 to 5 ) from core of the proposed PCF and $\Lambda$ shows used pitch in this manuscript. Pitch is generally termed for either distance between two adjacent rings of airholes or radius of the first airhole ring. In this manuscript, we have taken pitch $(\Lambda)$ and side of the square airhole (S) equal to $1.2 \mu \mathrm{m}$ and $0.85 \mu \mathrm{m}$, respectively. Hence, the HPD ratio $(\mathrm{S} / \Lambda)$ for the propounded $\mathrm{PCF}$ is 0.70 . Although many current fabrication technologies are available but larger HPD ratio (i.e. more than 0.90) is cumbersome to be realized practically via fabrication. Therefore, we have proposed a simple fashioned structure and all parameters are selected well within the fabrication realization limit. The background should be transparent and displays a very low loss profile for the entire communication range. $\mathrm{SiO}_{2}$ fulfills the above stated requirements. Hence, $\mathrm{SiO}_{2}$ is selected as background material whose refractive index can be calculated as given below [11]

$R I_{\mathrm{SiO}_{2}}=\sqrt{1+\frac{0.6961 \lambda^{2}}{\lambda^{2}-0.004679}+\frac{0.4079 \lambda^{2}}{\lambda^{2}-0.01351}+\frac{0.8974 \lambda^{2}}{\lambda^{2}-97.9340}}$

A layer of $1 \mu \mathrm{m}$ for absorbing the unwanted scattering losses is used at the outer boundary of the proposed structure. Such a layer is commonly known as perfectly matched layer (PML). This structure has very low complexity with HPD ratio equals to 0.70 and fabrication complexity will be low with such low HPD ratio. Many advanced techniques are available in this modern era for PCF fabrication. 3-D printing and extrusion techniques are cutting edge technology for PCF fabrication [23-24]. Recently in 2011, Atakaramians et al. in his literature showed that extrusion method is suitable for square hole fabrication [24]. In this method, the fiber is drawn from bulk glass and with the help of mandrel element any required shape of air holes, especially square one can be easily fashioned. Fused preforms is another substitute technique for fiber fabrication [25]. Preforms technique provides minimum distortion error while designing the fiber and it is the best suitable technique for low as well as high HPD ratio. In this method, fiber can be drawn by fusing two or more dissimilar glasses. Etching is applied subsequent to this and after this process PCF of required material is only left. By applying preforms nearly any shape of air holes can be delineated.

Stack \& draw and Sol-gel methods are other prime PCF fabrication techniques $[10,26]$. With the use of square/circular shaped mandrel element, we can fabricate the square/circular air holes with fine precision in the PCF. 


\section{Numerical Analysis:}

We have probed the entire structure with PML by using fully vectored FEM. In order to analyze the structure, the whole cross section is dissected into triangular subsections with the PML layer. The Mesh analysis is applied to these triangular subsections of the propounded structure with the perfectly matched electric field and magnetic field boundary conditions. PCF crosssection is subdivided into 10345 domain elements, 1821 boundary elements and 73166 number of degrees of freedom. Following is the solution of Maxwell equations for PCF subsections with the help of FEM that is as follows [13]

$\nabla \times\left([M]^{-1} \nabla \times \vec{E}-k_{0}^{2} n^{2}[M] \vec{E}\right)=0$

Here, E denotes electric field, $[\mathrm{M}] \&[\mathrm{M}]^{-1}$ depict PML and inverse PML matrix, respectively and $k_{0}=\frac{2 \pi}{\lambda}$ represents free space wavenumber. Effective refractive index $\left(n_{e f}\right)$ is related to propagation constant $(\beta)$ of the fiber as shown below

$\beta=n_{e f} k_{0}$

The phase or modal birefringence can be calculated with eqn. 5 [13]:

$B(\lambda)=\left|n_{e f}^{x-p o l}-n_{e f}^{y-p o l}\right|$

Group birefringence $G(\lambda)$ is closely associated with phase birefringence $B(\lambda)$. An important property of fiber in telecommunication is polarization mode dispersion $(\mathrm{PMD}=\mathrm{G}(\lambda) / \mathrm{c})$ which is directly related to $G(\lambda)$ and it should be minimum in order to minimize PMD. Group birefringence can be estimated using following relation [27]:

$\mathrm{G}(\lambda)=B(\lambda)-\lambda \frac{d B(\lambda)}{d \lambda}$

Dispersion profile for the recommended structure can be evaluated by following given relation [13]

$\mathrm{d}(\mathrm{ps} / \mathrm{nm} / \mathrm{km})=\frac{\lambda}{C} \frac{d^{2}\left(n_{e f}\right)}{d \lambda^{2}}$

Where c denotes speed of light, $\lambda$ shows the used wavelength and $n_{e f}$ displays effective refractive index of the recommended structure.

Nonlinear properties of the fiber are associated with the nonlinear coefficient of PCF and many properties such as supercontinuum generation, four-wave mixing and solitons generation depend on high nonlinear coefficient values. It can be calculated as follows [1]:

$\gamma\left(W^{-1} \mathrm{Km}^{-1}\right)=\frac{2 \pi n_{\mathrm{SiO}_{2}}}{\lambda A_{\text {eff }}}$

Where $n_{\mathrm{SiO}_{2}}$ denotes the nonlinear refractive index of $\mathrm{SiO}_{2}$ [13], $\lambda$ designates for operating frequency and $A_{\text {eff }}$ stands for an effective area of the PCF. 
Effective (modal) area $\left(A_{\text {eff }}\right)$ is the area of mode light concentration in the PCF and it can be formulated as follows [1]:

$A_{e f f}\left(\mu m^{2}\right)=\frac{\left[\int I(r) r d r\right]^{2}}{\left[\int I^{2}(r) d r\right]^{2}}$

Where $\mathrm{I}(\mathrm{r})=\left|E_{t r}\right|^{2}$ denotes transverse electric field $\left(E_{t r}\right)$ intensity distribution in the proposed structure.

The loss incurred by deviation of mode light intensity from core to the cladding of PCF is known as confinement which can be evaluated with eqn. (10) [12]

Confinement loss $(\mathrm{dB} / \mathrm{m})=8.686 \times k_{0} \times \operatorname{Img}\left(n_{e f}\right)$

Where $\operatorname{Img}\left(n_{e f}\right)$ displays the imaginary part of obtained effective refractive index (ERI).

High NA ensures high power carrying capacity of the fiber. Modal area of fiber is related to numerical aperture (NA) as given below [13]

$N A=\left[1+\frac{\pi A_{e f f}}{\lambda^{2}}\right]^{-1 / 2}$

Here $\lambda$ represents the operating wavelength.

The power of the fundamental mode of PCF is asymmetrically distributed in cladding, core and background material. Such distribution of mode power in the cladding, core and background material of the PCF is estimated with eqn. (12) [28].

Power Fraction $(\mathrm{PF})=\frac{\int_{\mathcal{J}} S_{Z} d A}{\int_{A l l} S_{Z} d A}$

Where $\mathcal{J}$ indicates the intended area (core, cladding \& background material) for PF calculation and $\int_{A l l}$ denote the entire cross-sectional area of PCF.

V-parameter of PCF can be calculated by using eqn. (13). A fiber behaves as single mode fiber for $V_{\text {eff }} \leq 2.405$ while for $V_{\text {eff }} \geq 2.405$ fiber displays multimode nature [29].

$V_{e f f}=\frac{2 \pi r}{\lambda} \sqrt{n_{c o}^{2}-n_{c l a d}^{2}}$

Here $\mathrm{r}$ denotes the radius of the fiber core, $n_{c o}$ represents ERI of core and $n_{\text {clad }}$ depicts ERI of PCF cladding.

Beat length of the fiber is nearly associated with birefringence and can be formulated as [29]

Beat Length $(\mu \mathrm{m})=\frac{\lambda}{B(\lambda)}$

\section{Results and discussions:}

This section thoroughly describes the change in optical specifications such as birefringence, group birefringence, nonlinearity, confinement loss, dispersion, numerical aperture, and effective V-parameter for the changes in core airhole diameter (d) and HPD ratio $(\mathrm{S} / \Lambda)$. 
Structural parameters can vary with an anomaly in the designing parameter in the fabrication process. Hence, fabrication tolerance is taken up to $\pm 2 \%$.

(a)

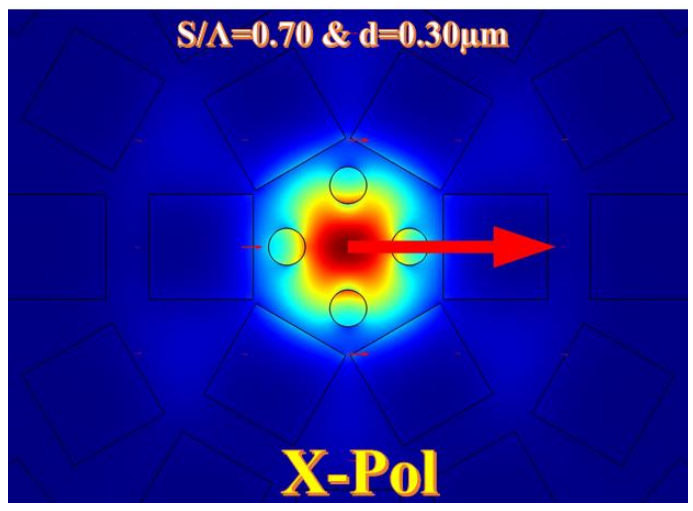

(b)

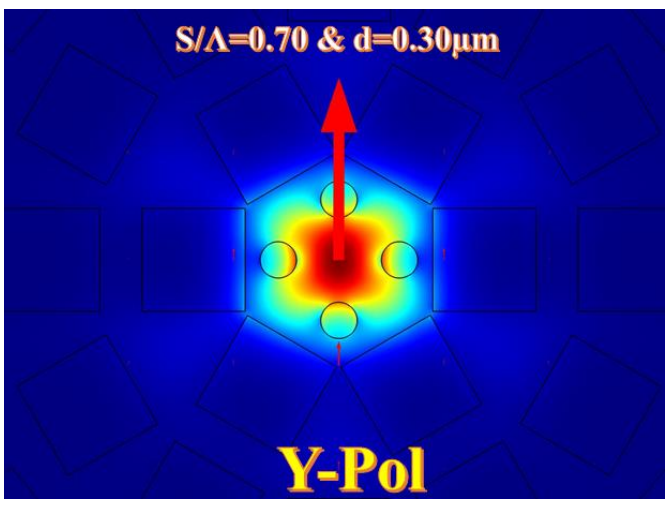

Fig. 2: Electric field distribution of the fundamental core mode of the proposed structure (a) for $x$ - polarization (b) for $y$-polarization, respectively.

Fig. 2(a)-(b) describes the electric field placement in the core of the proposed structure for $x$ and $y$-polarization, respectively. The fundamental core mode is located well in the core holes which defines that mode light concentrates in the small effective core area. Such mode field confinement is required for the low loss fiber.
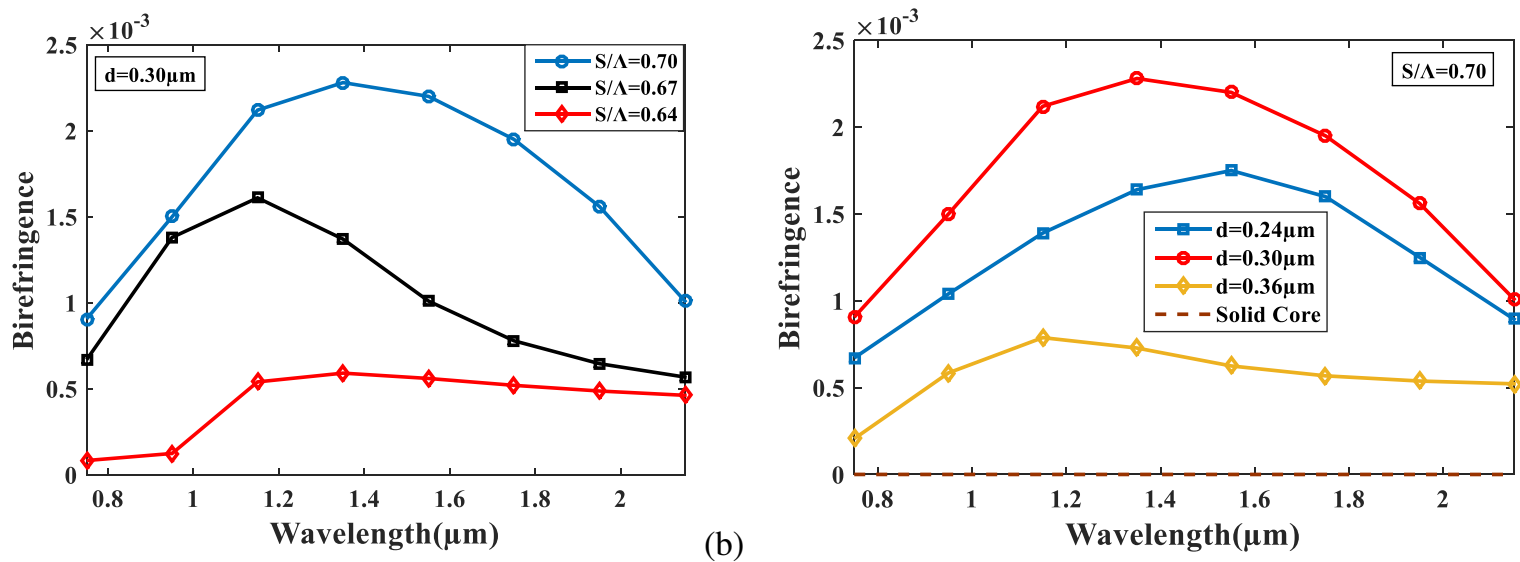

(a)

Fig. 3: The Birefringence versus wavelength curve for the variation in (a) HPD ratio and (b) diameter of circular core airhole.

The change in phase birefringence with variation in operating wavelength is revealed in Fig. 3(a)-(b). Birefringence value increases with an increase in the HPD ratio. As we increase the HPD ratio, the difference between $x$ - and $y$-polarized core electric field increases. Therefore, the highest birefringence of $2.40 \times 10^{-3}$ is observed for $\mathrm{S} / \Lambda=0.70$. However, maximum birefringence of $2.40 \times 10^{-3}$ is also obtained for core airhole diameter (d) equals to $0.30 \mu \mathrm{m}$ as shown in Fig. 3(b). Therefore, the propounded structure can be used as polarization maintaining fiber and polarization splitter for these high birefringence values. 

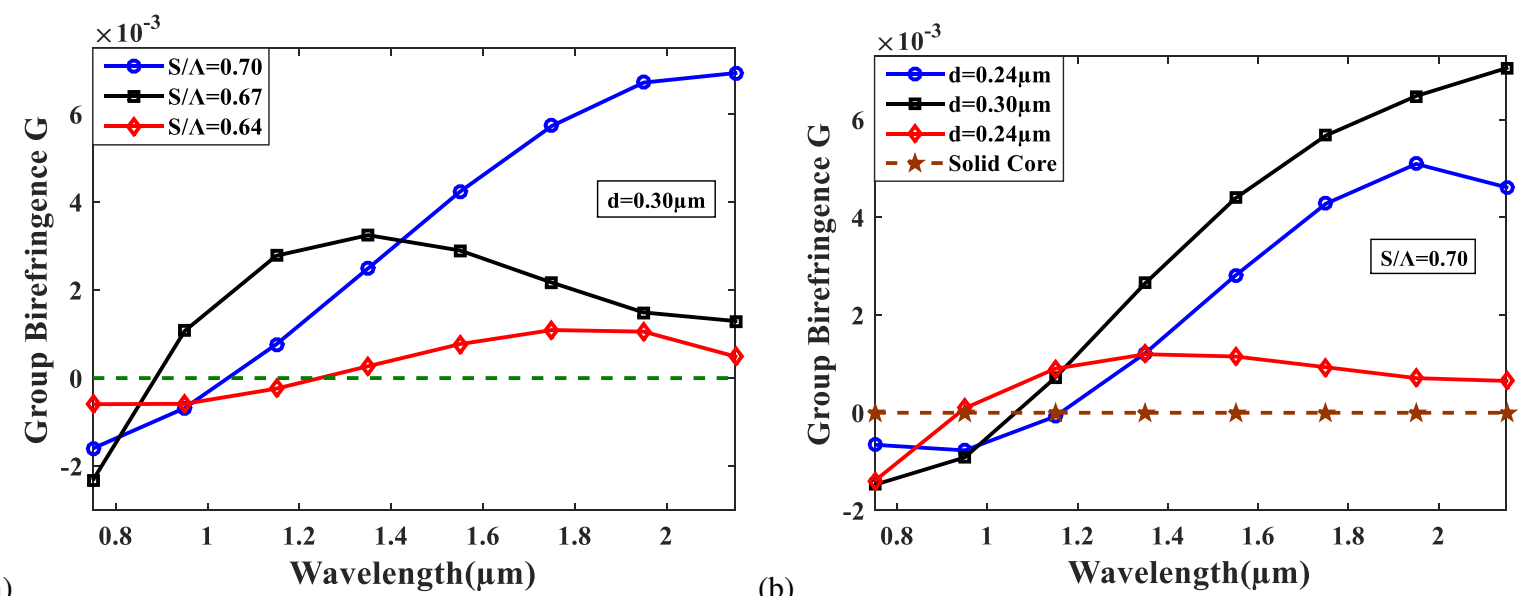

Fig. 4: The group birefringence deterrence with wavelength for the variation in (a) HPD ratio and (b) circular core airhole diameter.

Group modal birefringence variation with wavelength is shown in Fig. 4(a)-(b). Group birefringence is almost increasing with wavelength which is the contrast behavior as compared to phase birefringence. The negative slope of birefringence versus wavelength contributes to the increasing behavior of group birefringence. It is negative over 0.8-1.2 $\mu \mathrm{m}$ and increases to maximum value of $6.93 \times 10^{-3}$ for $S / \Lambda=0.70$ as shown in Fig. 4(a). However, the minimum $G(\lambda)$ is obtained for $S / \Lambda=0.63$. The same behavior of group birefringence is observed for the core airhole diameter variation as shown in Fig. 4(b) and it is noticeable that for solid core, the achieved $G(\lambda)$ is of $10^{-7}$ order. Hence, the proposed fiber can be used in high bit data rate communication.
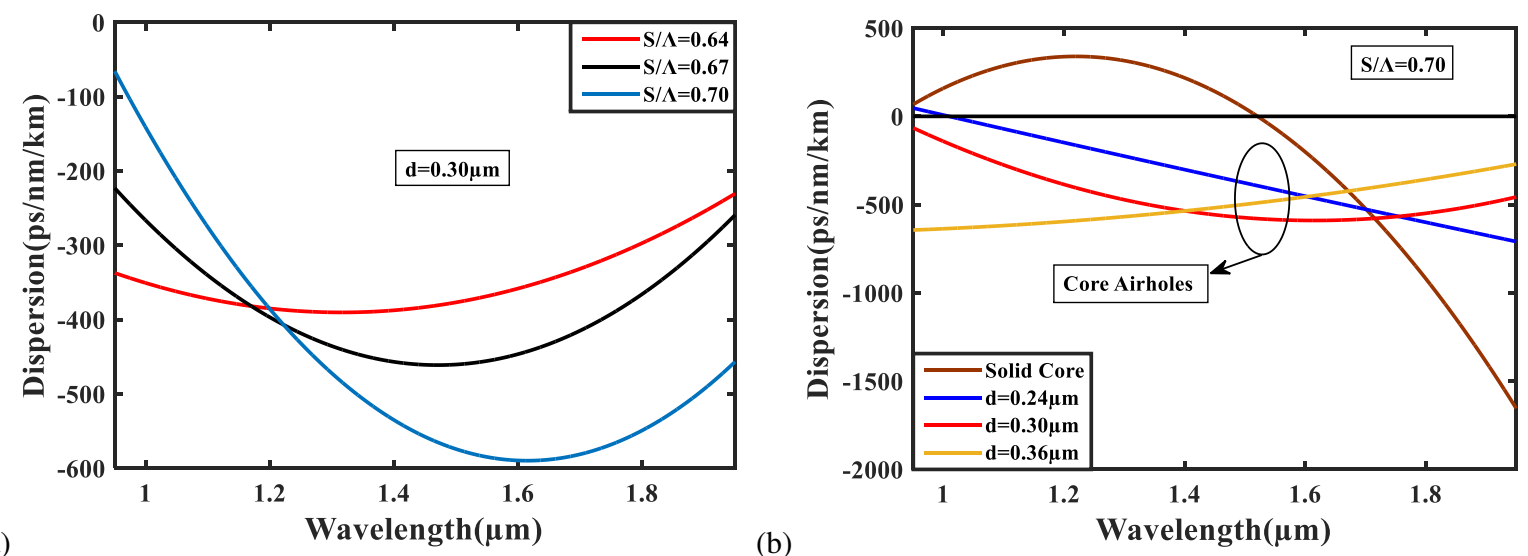

Fig. 5: The figure of dispersion deviation with wavelength for the change in (a) HPD ratio and (b) diameter of circular core airhole.

The dispersion profile of a structure over a communication window should be as small as possible in order to negate the positive material dispersion. The material dispersion of a fiber is always positive. While waveguide dispersion of fiber can be amended with the structural change in fiber waveguide. Here, Fig. 5(a)-(b) displays the dispersion profile variation of the 
recommended structure with respect to operating wavelength. Improving the HPD ratio of the proposed structure also improves negative dispersion as shown in Fig. 5(a). The largest negative dispersion value achieved with the configured structure is $-597 \mathrm{ps} / \mathrm{nm} / \mathrm{km}$ for $\mathrm{S} / \Lambda$ equals to 0.70 at $1.55 \mu \mathrm{m}$. While almost totally negative dispersion is obtained for the core diameter variation as shown in Fig. 5(b). However, the maximum negative dispersion of -1689 $\mathrm{ps} / \mathrm{nm} / \mathrm{km}$ is obtained for the solid core at $1.95 \mu \mathrm{m}$ wavelength. Thus, such a large negative dispersion endorsed that the propounded structure could be applicable as residual dispersion compensator.
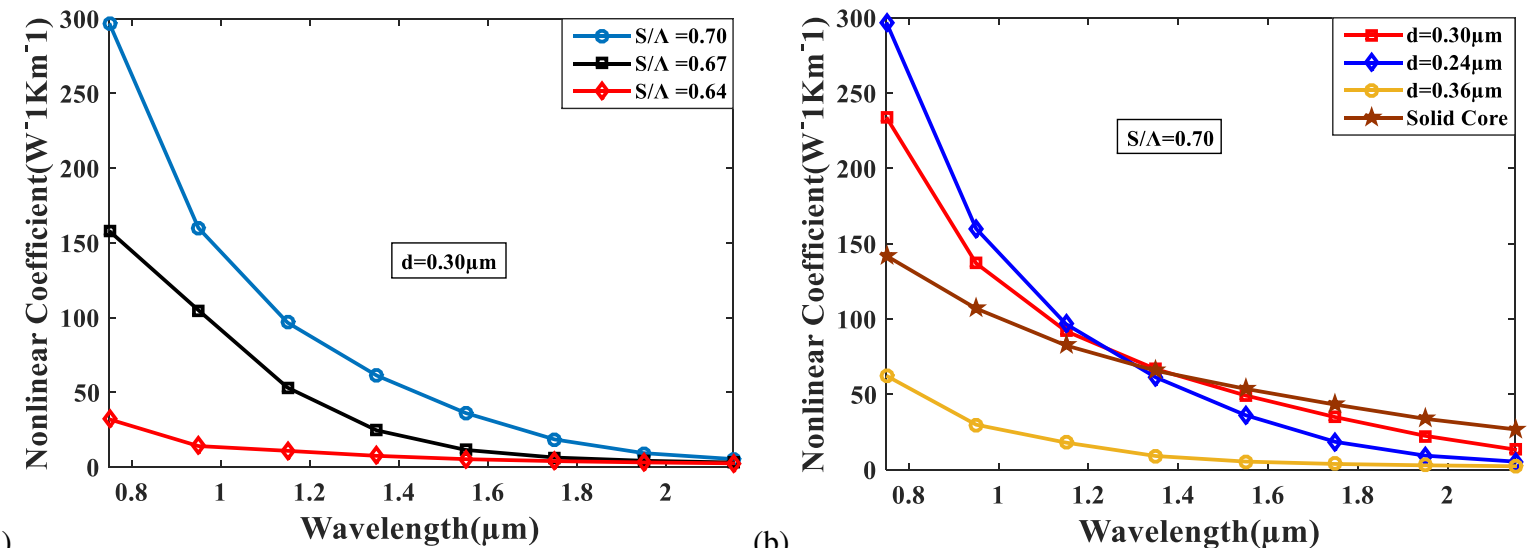

(b)

Wavelength $(\mu \mathrm{m})$

Fig. 6: Variation in nonlinearity values with change in operating wavelength for the divergent values of (a) HPD ratio and (b) circular core airhole diameter.

The change in nonlinearity for divergent values of operating wavelength is shown in Fig. 6(a)(b) for the change in HPD ratio and core airhole diameter, respectively. From figures, it is obvious that numeric nonlinearity decreases with operating wavelength for both types of structural variations. The highest nonlinearity of $300 \mathrm{~W}^{-1} \mathrm{Km}^{-1}$ is obtained for both HPD ratio $(\mathrm{S} / \Lambda)$ and core airhole diameter $(\mathrm{d})$ values of 0.70 and $0.24 \mu \mathrm{m}$ at $0.75 \mu \mathrm{m}$. It is the highest achieved value of nonlinearity for any proposed structure without introducing ellipse in PCF core or without doping of any foreign high nonlinear RI material in best of the author's knowledge. With such huge nonlinearity, the proposed PCF can be used for supercontinuum generation as well as for solitons generation. 

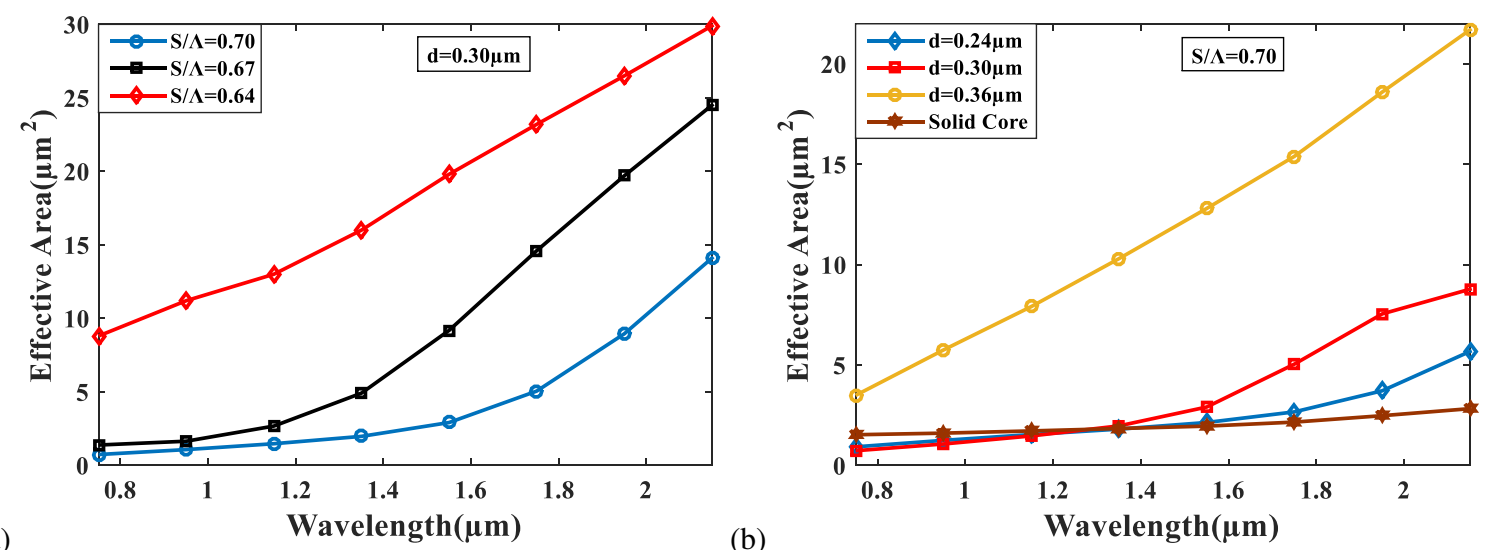

Fig. 7: The graph of effective area variation with wavelength for the change in (a) HPD ratio and (b) diameter of circular core airhole.

Effective or modal area of fundamental core mode describes that how well a core mode intensity is confined with small core area. Fig. 7(a)-(b) shows the $A_{\text {eff }}$ variation with wavelength for change in HPD ratio and core airhole diameter, respectively. It is seen from figures that $A_{\text {eff }}$ increases with wavelength. From Fig. 7(a), it is seen that $A_{\text {eff }}$ decreases with HPD ratio. In the same way increasing the core airhole diameter also increases the modal area as shown in Fig. 7(b). The lowest obtained value is $0.734 \mu \mathrm{m}^{2}$ for both $\mathrm{S} / \Lambda$ and $\mathrm{d}$ equal to 0.70 and $0.24 \mu \mathrm{m}$ at $0.75 \mu \mathrm{m}$ operating wavelength.
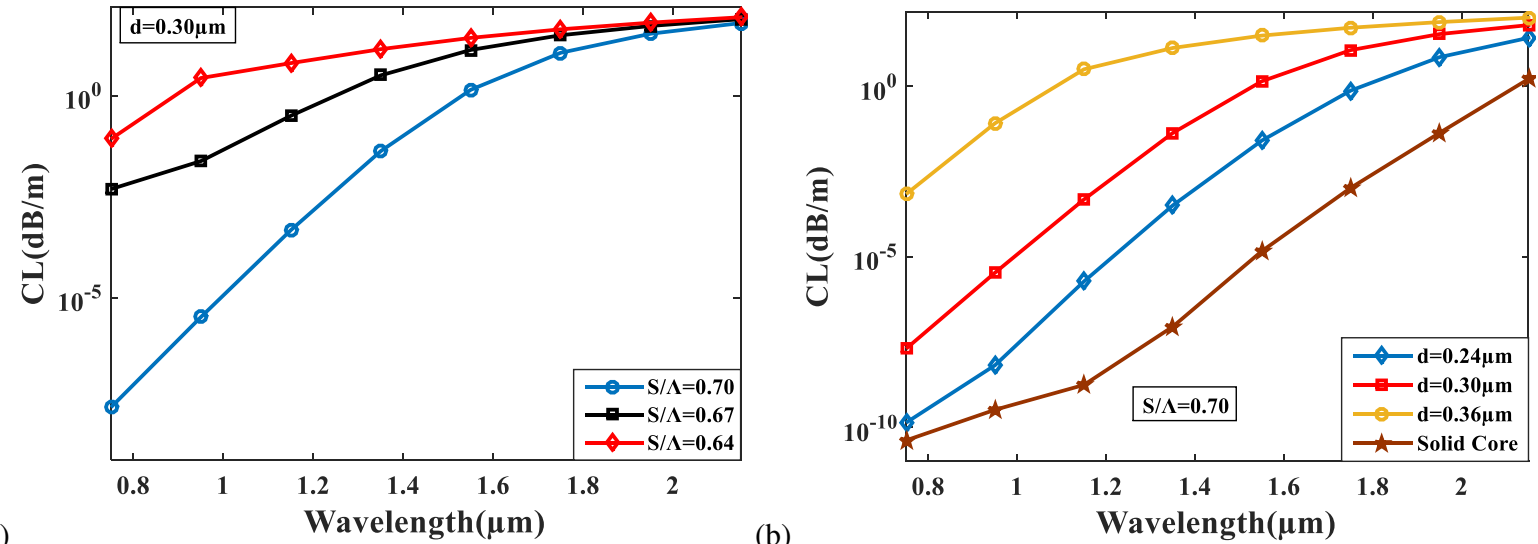

Fig. 8: Change in confinement loss (CL) with operating wavelength for the different values of (a) HPD ratio and (b) circular core airhole diameter.

The fundamental mode light diffuses into the cladding area as it propagates along fiber length. Such deviation of light from the core region induces loss which generally termed as confinement loss (CL). CL increases with an increase in wavelength. CL decreases with HPD ratio as shown in Fig. 8(a). While CL increases with the core airhole diameter as shown in Fig. 8(b). The minimum obtained values of $C L$ are $2.01 \times 10^{-8} \mathrm{~dB} / \mathrm{m}$ and $4.12 \times 10^{-11} \mathrm{~dB} / \mathrm{m}$, respectively for $\mathrm{S} / \Lambda=0.70$ and solid core at $0.75 \mu \mathrm{m}$. Henceforth, the propounded PCF could be a potential candidate for low loss waveguide application with such an ultra-low CL. 

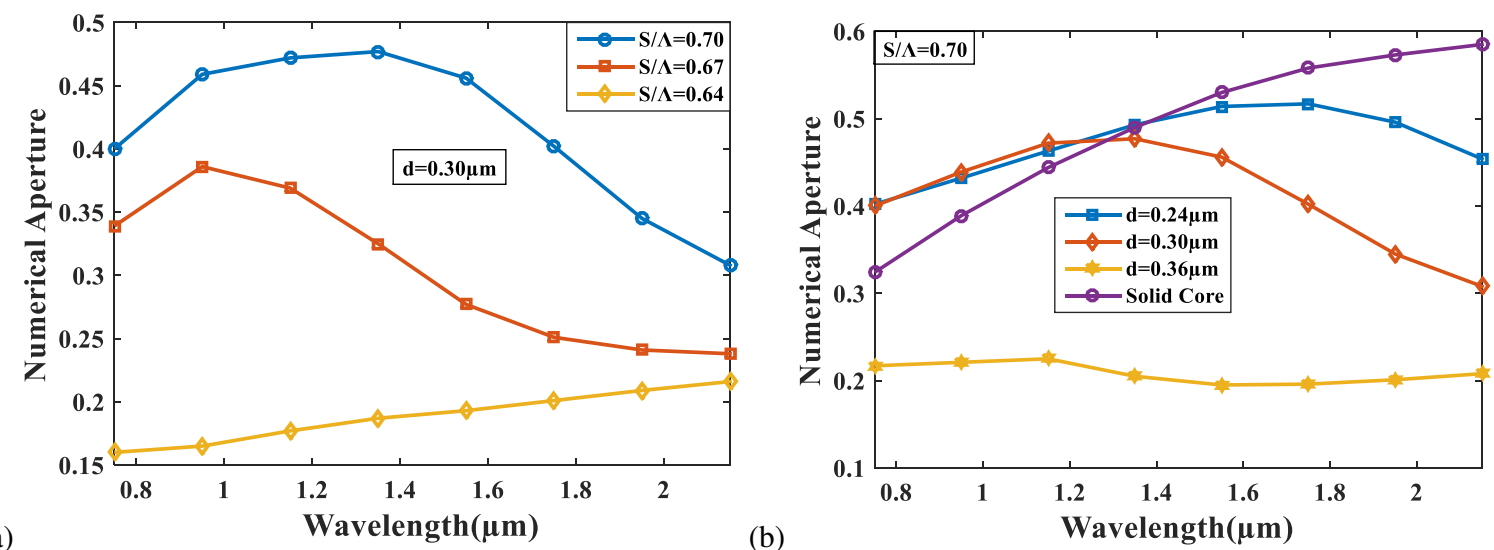

Fig. 9: Variation in numerical aperture (NA) values with change in operating wavelength for the divergent values of (a) HPD ratio and (b) circular core airhole diameter.

The change in NA with operating wavelength is shown in Fig. 9(a)-(b). From Fig. 9(a), it is seen that increasing the HPD ratio increases NA of the structure. The maximum NA of 0.48 is obtained for $S / \Lambda=0.70$. While from Fig. $9(\mathrm{~b})$, it is noted that increasing the hole diameter decreases the NA of the structure. Therefore, the highest NA of 0.59 is achieved for the solid core variant of the proposed PCF. Such a high value of NA of the propounded structure makes it suitable for bio-medical imaging applications.

Table 1: A Comprehensive summary of different optical parameter values for different sets of structural parametric variations.

\begin{tabular}{|c|c|c|c|c|c|c|c|}
\hline \multicolumn{2}{|c|}{ Parametric Variations } & \multirow{2}{*}{$\begin{array}{c}\mathbf{B}(\lambda) \\
2.40 \times 10^{-3}\end{array}$} & \multirow{2}{*}{$\begin{array}{c}\mathbf{G}(\boldsymbol{\lambda}) \\
-1.59 \times 10^{-3}\end{array}$} & \multirow{2}{*}{$\begin{array}{c}\gamma \\
\left(\mathbf{W}^{-\mathbf{1}} \mathbf{K m}^{-\mathbf{1}}\right) \\
300\end{array}$} & \multirow{2}{*}{$\begin{array}{c}\mathbf{d}(\mathbf{p s} / \mathbf{n m} / \mathbf{k m}) \\
-597\end{array}$} & \multirow{2}{*}{$\begin{array}{c}\begin{array}{c}\mathbf{C L} \\
(\mathbf{d B} / \mathbf{m})\end{array} \\
2.01 \times 10^{-8}\end{array}$} & \multirow{2}{*}{$\begin{array}{l}\mathbf{N A} \\
0.48\end{array}$} \\
\hline \multirow{3}{*}{$\begin{array}{c}\text { Pitch } \\
\text { Variation } \\
(\mathbf{S} / \mathbf{\Lambda})\end{array}$} & 0.70 & & & & & & \\
\hline & 0.67 & $1.72 \times 10^{-3}$ & $-2.32 \times 10^{-3}$ & 158 & -461.2 & $4.7 \times 10^{-3}$ & 0.39 \\
\hline & 0.64 & $5.91 \times 10^{-4}$ & $-5.95 \times 10^{-4}$ & 33 & -389.7 & $8.48 \times 10^{-2}$ & 0.22 \\
\hline \multirow{4}{*}{$\begin{array}{c}\text { Core } \\
\text { Airhole } \\
\text { diameter } \\
\text { Variation(d) }\end{array}$} & $0.24 \mu \mathrm{m}$ & $2.40 \times 10^{-3}$ & $-6.55 \times 10^{-4}$ & 300 & -709.3 & $1.36 \times 10^{-10}$ & 0.52 \\
\hline & $0.30 \mu \mathrm{m}$ & $1.81 \times 10^{-3}$ & $-1.4 \times 10^{-3}$ & 234 & -589.9 & $2.01 \times 10^{-8}$ & 0.48 \\
\hline & $0.36 \mu \mathrm{m}$ & $7.93 \times 10^{-4}$ & $-1.41 \times 10^{-3}$ & 62.4 & -643.8 & $6.84 \times 10^{-4}$ & 0.23 \\
\hline & Solid Core & $3.03 \times 10^{-7}$ & $4.81 \times 10^{-7}$ & 142 & -1689 & $4.12 \times 10^{-11}$ & 0.59 \\
\hline
\end{tabular}

Table 1 shows inclusive summary of optical parameter variations against variations in the structural parameter of the proposed PCF. Here, we have observed that maximum birefringence and nonlinear coefficient are obtained for perforated core of propounded PCF at $\mathrm{S} / \Lambda=0.70$ and $\mathrm{d}=0.24 \mu \mathrm{m}$. Whereas, maximum NA, dispersion, confinement loss and minimum $\mathrm{G}(\lambda)$ are observed for solid core variant of the propounded structure. Therefore, for high birefringence 
and nonlinear coefficient, we have to choose perforated core while in the case of dispersion, confinement loss and NA, we should go for solid core variant.

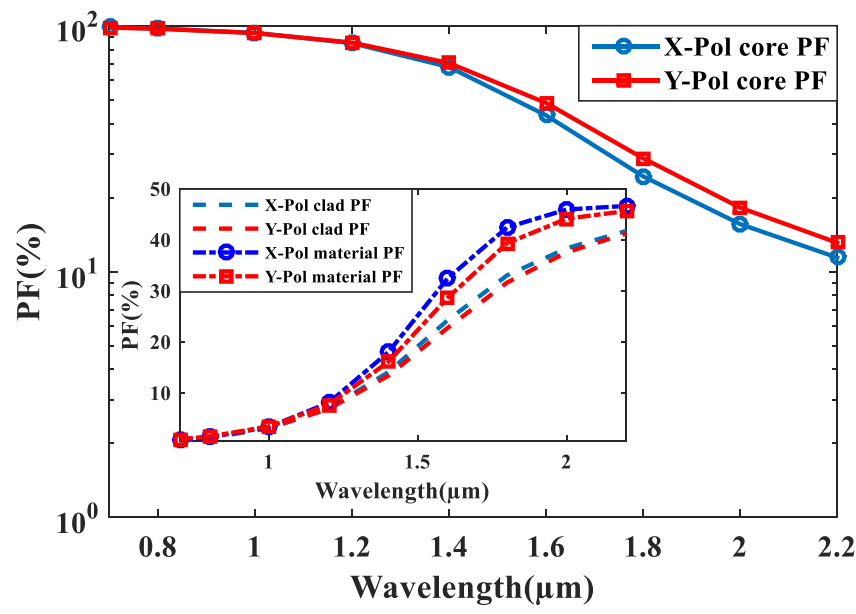

Fig. 10: The change in power fraction of the core with variation in operating wavelength for HPD ratio of 0.70 and a circular core airhole diameter of $0.30 \mu \mathrm{m}$.

Fig. 10 shows the variation in core power fraction (CPF) with wavelength. The power decreases with an increase in operating wavelength. The $x$-pol mode power decreases faster as compared to $y$-pol mode power. Whereas from Fig. 10, it is to be mentioned that cladding and material power fraction is increasing with wavelength because the core mode power diffuses into cladding area and background material. The highest core mode power of $99.98 \%$ is obtained at $0.75 \mu \mathrm{m}$ which ensures high power carrying capacity of the proposed structure.
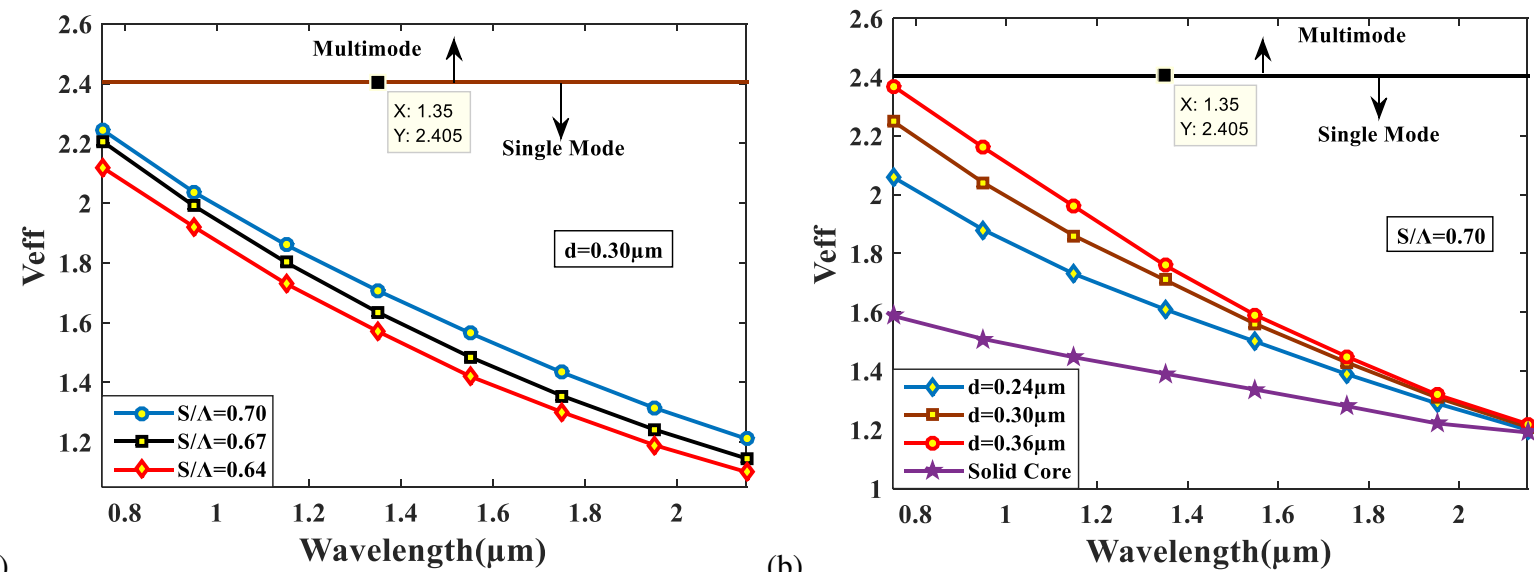

Fig. 11: The diversion in $V_{e f f}$ with different operating wavelengths for the divergent values of (a) HPD ratio and (b) circular core airhole diameter.

Fig. 11 shows the effective V-parameter variation with wavelength. From Fig. 11(a)-(b), it is to be noticed that $V_{\text {eff }}$ decreases with wavelength for both HPD ratio $(\mathrm{S} / \Lambda)$ and diameter $(\mathrm{d})$ of core air holes. The proposed PCF behaves as single mode fiber for the whole operating wavelength range as seen in Fig. 11. Hence, it can be easily said that the submitted PCF shows endlessly single mode behaviors. 


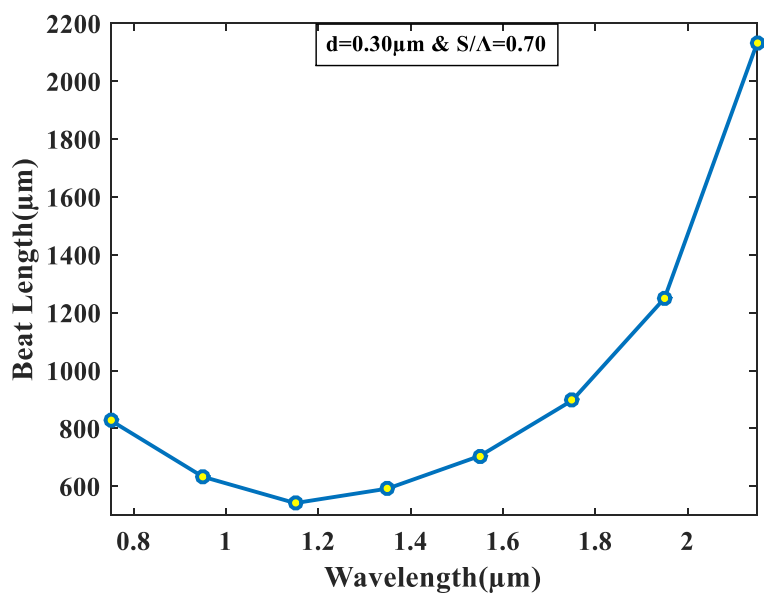

Fig. 12: The plot of deviation in beat length for the change in operating wavelength at core hole diameter of $0.30 \mu \mathrm{m}$ and $\mathrm{HPD}$ ratio $(\mathrm{S} / \Lambda)$ equals to 0.70 .

Fig. 12 depicts the variation in beat length values against change in operating wavelength values and it can be calculated by using eqn. 14. The minimum observed value $542 \mu \mathrm{m}$ is achieved at $1.15 \mu \mathrm{m}$ operating wavelength. In order to use the propounded structure as polarization maintaining fiber, we have to select lower beat length value. Such considerable low beat length value allows the recommended structure to be used as polarization maintaining fiber.

Table 2: A comparison of optical parameters between propounded structure and existing PCF structures.

\begin{tabular}{|c|c|c|c|c|c|c|}
\hline Ref./year & $\begin{array}{c}\mathrm{CPF} \\
(\%)\end{array}$ & $\begin{array}{c}\mathrm{d} \\
(\mathrm{ps} / \mathrm{nm} / \mathrm{km})\end{array}$ & $\begin{array}{c}\gamma\left(\mathrm{W}^{-1} \mathrm{Km}^{-}\right. \\
{ }^{1}\end{array}$ & Single/multimode & $\begin{array}{c}\mathrm{CL} \\
(\mathrm{dB} / \mathrm{m})\end{array}$ & $\mathrm{G}(\lambda)$ \\
\hline$[9] /[2008]$ & - & -187 & - & - & $10^{-6}$ & - \\
\hline$[20] /[2013]$ & - & -20 & - & - & $10^{-8}$ & - \\
\hline$[30] /[2014]$ & - & -930 & 58 & Single/multimode & $10^{-5}$ & - \\
\hline$[10] /[2015]$ & - & -750 & - & - & $10^{-6}$ & - \\
\hline$[17] /[2015]$ & - & - & - & - & $10^{-4}$ & - \\
\hline$[31] /[2016]$ & - & - & - & - & $10^{-2}$ & - \\
\hline$[11] /[2019]$ & - & -1550 & - & Single mode & 3.15 & - \\
\hline$[12] /[2019]$ & - & -120 & - & - & $10^{-5}$ & - \\
\hline$[32] /[2019]$ & - & -90 & 75 & - & $10^{-3}$ & - \\
\hline$[13] /[2020]$ & - & -2600 & 148 & - & $10^{-9}$ & - \\
\hline $\begin{array}{c}\text { Proposed } \\
\text { Work }\end{array}$ & 99.98 & -1689 & 300 & Single mode & $10^{-11}$ & $10^{-7}$ \\
\hline
\end{tabular}

From Table 2, it is concluded that proposed work displays better numeric values of listed optical parameters as compared to existing research articles. Thus, the propounded PCF is far better than previous existing literatures. Here, it is worth to be mentioned that group 
birefringence i.e. $G(\lambda)$ is included for the first time in any simple PCF structure consisting air holes in its core and cladding regions.

\section{Conclusion:}

An unadorned optimized perforated core PCF is designed using FEM in this manuscript. The recommended structure shows a very high nonlinear coefficient of $300 \mathrm{~W}^{-1} \mathrm{Km}^{-1}$ with a high core power fraction equals to $99.98 \%$. Large negative dispersion of $-1689 \mathrm{ps} / \mathrm{nm} / \mathrm{km}$ is obtained for the solid core variant of the propounded PCF. The structure has very high phase birefringence equals to $2.35 \times 10^{-3}$ with high numerical aperture equals to 0.59 . The propounded structure behaves as endlessly single mode fiber with very low confinement loss of $4.12 \times 10^{-11}$ $\mathrm{dB} / \mathrm{m}$ and beat length of $542 \mu \mathrm{m}$. We have to choose a solid core for large negative dispersion while perforated core must be chosen for high birefringence and nonlinearity. With such desirable characteristics of optimized PCF ensures variety of applications such as supercontinuum generation, dispersion compensation, solitons generation, polarization maintenance and high bit data rate transmission.

\section{Compliance with ethical standards}

Conflict of interest: There are no conflicts of interest to declare

\section{References:}

[1] Y. E. Monfared, S. A. Ponomarenko "Extremely nonlinear carbon-disulfide-filled photonic crystal fiber with controllable dispersion," Optical Materials 88, 406-411, (2019).

[2] S.S.F. Poli, A. Cucinotta, "Photonic Crystal Fiber, Properties and Applications," Springer Ser. Mater. Sci., Springer, (2007).

[3] T. Yang, E. Wang, H. Jiang, Z. Hu, K. Xie, High birefringence photonic crystal fiber with high nonlinearity and low confinement loss, Opt. Express 23, 8329, (2015). https://doi.org/10.1364/OE.23.008329.

[4] G. D. Krishna, V. P. M. Pillai, K.G. Gopchandran, "Design of low dispersion and low loss photonic crystal fiber: Defected core circular-octagon hybrid lattices," optical fiber Technology 51, 17-24, (2019).

[5] F. Begum, Y. Namihira, S.A. Razzak, S. Kaijage, N.H. Hai, T. Kinjo, K. Miyagi, N. Zou, "Novel broadband dispersion compensating photonic crystal fibers: applications in high-speed transmission systems," Opt. Laser Technol. 41, 679-686, (2009).

[6] W. H. Reeves, J.C. Knight, P.S.J. Russell, P.J. Roberts, B.J. Mangan, “Dispersion flattened 
photonic crystal fibers at 1550nm," Optical Fiber Communication Conference, Optical Society of America, p. FI3, (2003).

[7] W.H. Reeves, J.C. Knight, P.S.J. Russell, P.J. Roberts, "Demonstration of ultra-flattened dispersion in photonic crystal fibers", Opt. Express 10, 609-613, (2002).

[8] K. Saitoh, M. Koshiba, T. Hasegawa, E. Sasaoka, "Chromatic dispersion control in photonic crystal fibers: application to ultra-flattened dispersion”, Opt. Express 11, 843-852, (2003).

[9] F.S. Marcos, A.R. Franco, Valdir A. Serrão, "Microstructured optical fiber for residual dispersion compensation over $\mathrm{S}+\mathrm{C}+\mathrm{L}+\mathrm{U}$ wavelength bands", IEEE Photonics Technol. Lett 20, 571-573, (2008).

[10] A. Medjouri, L.M. Simohamed, O. Ziane, A. Boudrioua, "Investigation Of High Birefringence And Chromatic Dispersion Management In Photonic Crystal Fiber With Square Air Holes," Optik -International Journal for Light and Electron Optics 126, 2269-2274, (2015), [11] Sugandha Das, Moutusi De, Vinod Kumar Singh, "Single mode dispersion shifted photonic crystal fiber with liquid core for optofluidic applications", Optical fiber technology 53, 102012, (2019).

[12] G. Dhanu Krishna, V.P. M. Pillai, K.G. Gopchandran, "Design of low dispersion and low loss photonic crystal fiber: Defected core circular-octagon hybrid lattices", Optical Fiber Technology 51, 17-24, (2019).

[13] A. Upadhyay, S. Singh, Y. K. Prajapati, R. Tripathi, "Numerical Analysis of Large Negative Dispersion and highly Birefringent Photonic Crystal Fiber" Optik-International Journal for Light and Electron Optics, 218, 164997, (2020).

[14] Y. Bo, Y. Li, L. Sun, "Characteristics analysis of photonic crystal fiber with octagonal hybrid cladding,” Optik-Int. J. Light Electron Opt. 127, 9828-9832, (2016).

[15] Y. Fei, Z. Wang, Y. Zhang, Y. Yu, C. Lv, "Analysis of a highly birefringent photonic crystal fiber with ellipse-rhombus air core,” Optik-Int. J. Light Electron Opt. 125, 6266-6269, (2014).

[16] M. F. H. Arif, M. J. H. Biddut, “A new structure of photonic crystal fiber with high sensitivity, high nonlinearity, high birefringence and low confinement loss for liquid analyte sensing applications," Sens. Bio-Sens. Res. 12, 8-14, (2017).

[17] H. Ademgil, S. Haxha, "PCF based sensor with high sensitivity, high birefringence and low confinement losses for liquid analyte sensing applications," Sensors 15, 31833-31842, (2015).

[18] D. Chen, S. Linfang, "Ultrahigh birefringent photonic crystal fiber with ultralow confinement loss," IEEE Photon. Technol. Lett. 19, 185-187, (2007). 
[19] K. Ahmed, M. Morshed, S. Asaduzzaman, M. F. H. Arif, “Optimization and enhancement of liquid analyte sensing performance based on square-cored octagonal photonic crystal fiber, Optik-Int. J. Light Electron Opt. 131, 687-696, (2017).

[20] Y. S. R. Hao, Z. Li, G. Sun, L. Niu, “Analysis on photonic crystal fibers with circular air holes in elliptical configuration," Optical Fiber Technology 19, 363-368, (2013).

[21] S. Ramachandran, P. Kristensen, M.F. Yan, "Generation and Propagation of Radially Polarized Beams in Optical Fibers,” Opt. Lett. 34, 2525-2527, (2009).

[22] X. Bai, H. Chen, H. Yang, "Design of a circular photonic crystal fiber with square airholes for orbital angular momentum modes transmission”, Optik- Int. J. Light Electron Opt. 158, 1266-1274, (2018).

[23] D. C. Allan, C. Soukoulis, "Photonic crystals and light localization in the 21st century", Kluwer, Dodrecht, Netherlands, vol. 563, 305-320, (2001). ISBN: 978-94-010-0738-2.

[24] S. Atakaramians, S. Afshar, H. E. Heidepriem, M. Nagel, B. M. Fischer, D. Abbott, T. M. Monro, “THz porous fibers: design, fabrication and experimental characterization," Opt. Exp. 17, 14053-14062, (2009).

[25] P. Falkenstein, C. D. Merritt, B. L. Justus, "Fused preforms for the fabrication of photonic crystal fibers," Optics Letters, 29, 1858-1860, (2004).

[26] J. C. Knight, T. A. Birks, P. St. J. Russell, and D. M. Atkin “All-silica single-mode optical fiber with photonic crystal cladding”, Opt. Lett. 21, 1547-1549, (1996).

[27] Y. Yue, G. Kai, Z. Wang, Y. Li, C. Zhang, Y. Lu, T. Sun, L. Jin, J. Liu, Y. Liu, S. Yuan, $\mathrm{X}$. Dong, "Phase and group modal birefringence of an index-guiding photonic crystal fibre with helical air holes," Optics Communications 268, 46-50, (2006).

[28] B. K. Paul, K. Ahmed, "Si7 $\mathrm{N}_{3}$ material filled novel heptagonal photonic crystal fiber for laser applications,” Ceramics International, 45, 1215-1218, (2019).

[29] K. Ahmed, "Ultra high birefringence and lower beat length for square shape PCF: Analysis effect on rotation angle and eccentricity," Alexandria Eng. J. 57, 3683-3691, (2018).

[30] M.I. Hasan, M. Selim Habib, M. Samiul Habib, S.A. Razzak, Highly nonlinear and highly birefringent dispersion compensating photonic crystal fiber, Opt. Fiber Technol. 20, 32-38, (2014).

[31] H. Ademgil, S. Haxha, "Highly birefringent nonlinear PCF for optical sensing of analytes in aqueous solutions,” Optik Int. J. Light Electron Optics 127, 6653-6660, (2016).

[32] M. De, V. K. Singh, "Multi-purpose photonic crystal fiber having advanced optical properties and long sensing range", Photonics and Nanostructures - Fundamentals and Applications 36, 100722-1-8, (2019). 


\section{Figures}

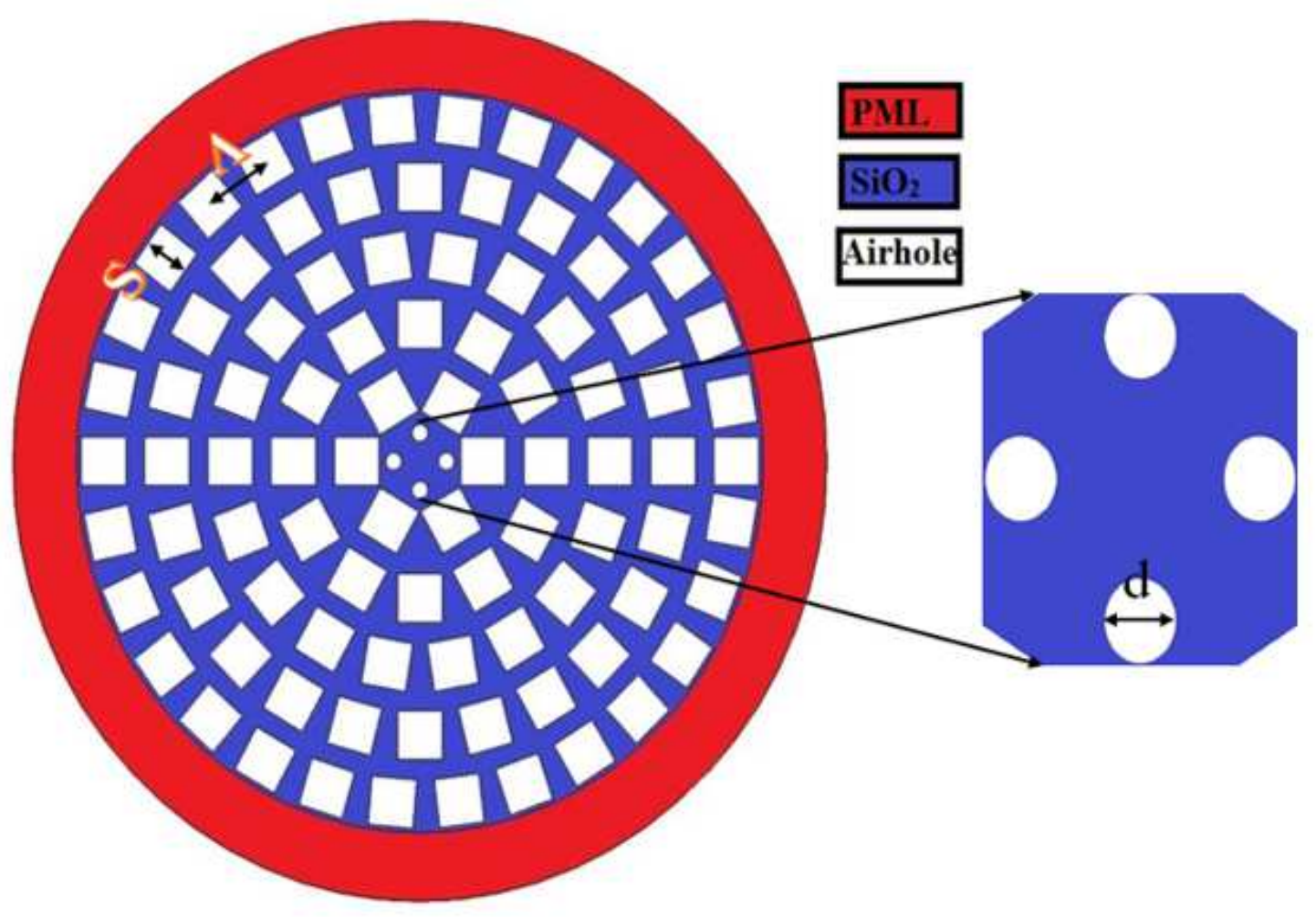

Figure 1

2D schematic of the square airhole cladding proposed PCF with enlarge view of the porous core section having circular air holes.

(a)

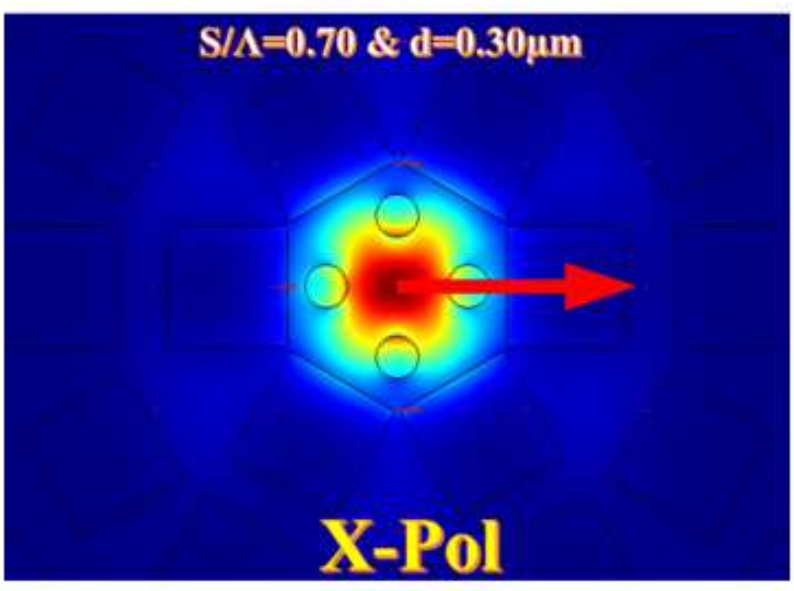

(b)

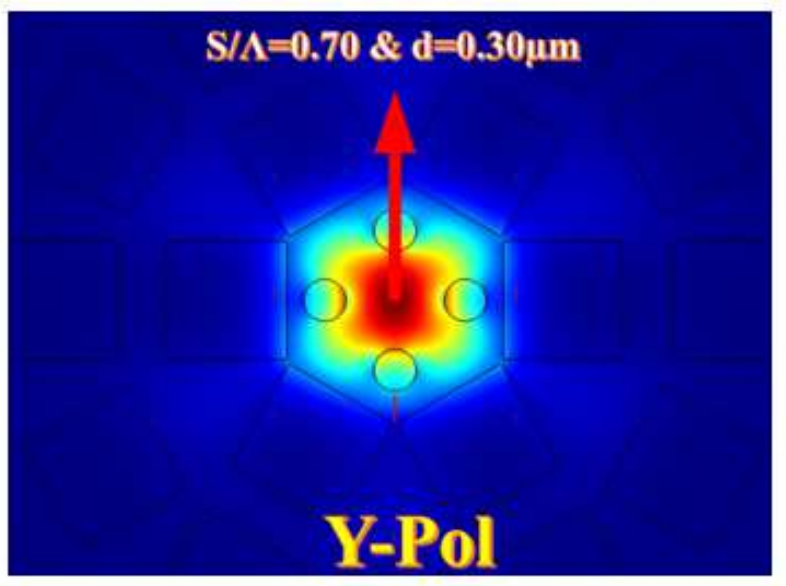

\section{Figure 2}

Electric field distribution of the fundamental core mode of the proposed structure (a) for x-polarization (b) for $y$-polarization, respectively. 

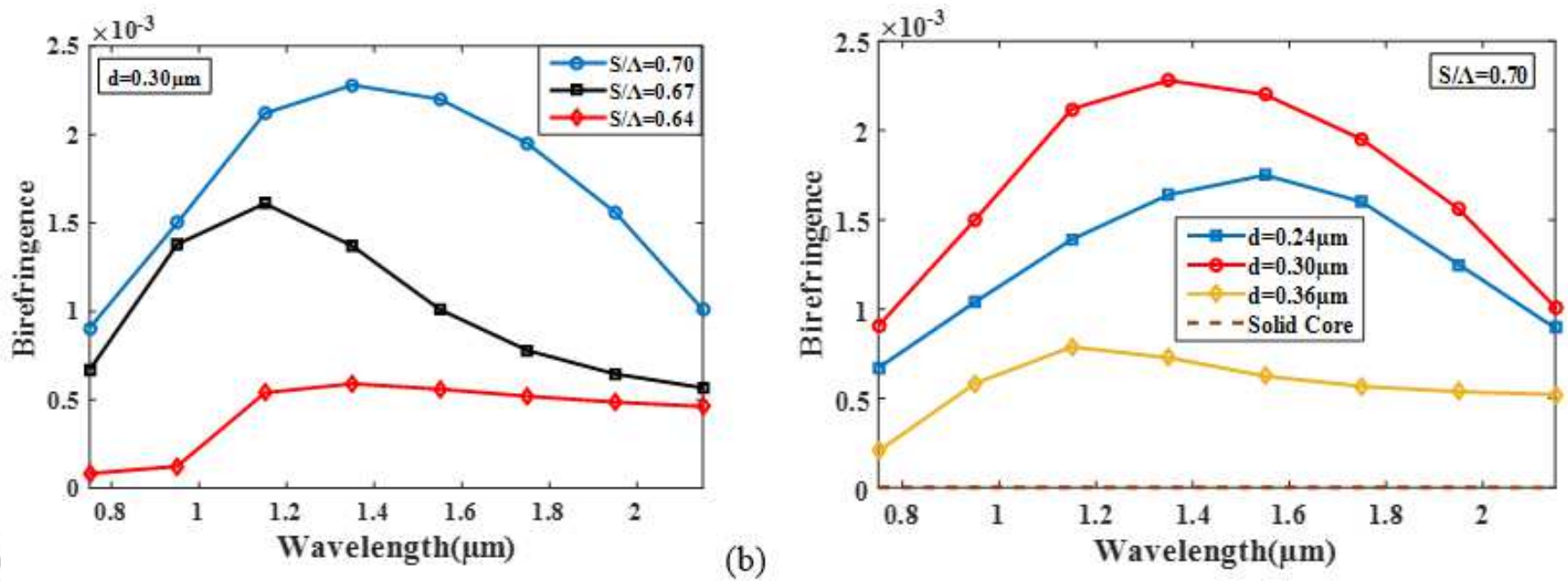

Figure 3

The Birefringence versus wavelength curve for the variation in (a) HPD ratio and (b) diameter of circular core airhole.
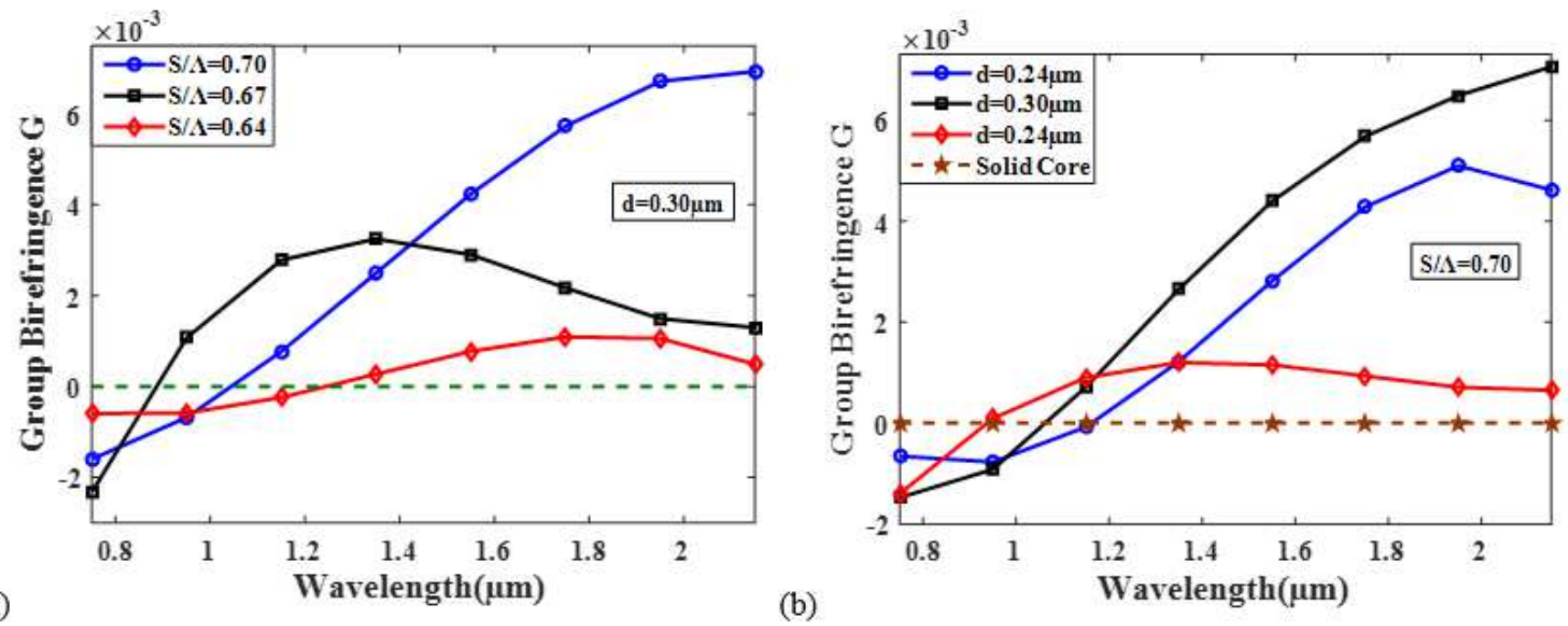

Figure 4

The group birefringence deterrence with wavelength for the variation in (a) HPD ratio and (b) circular core airhole diameter. 

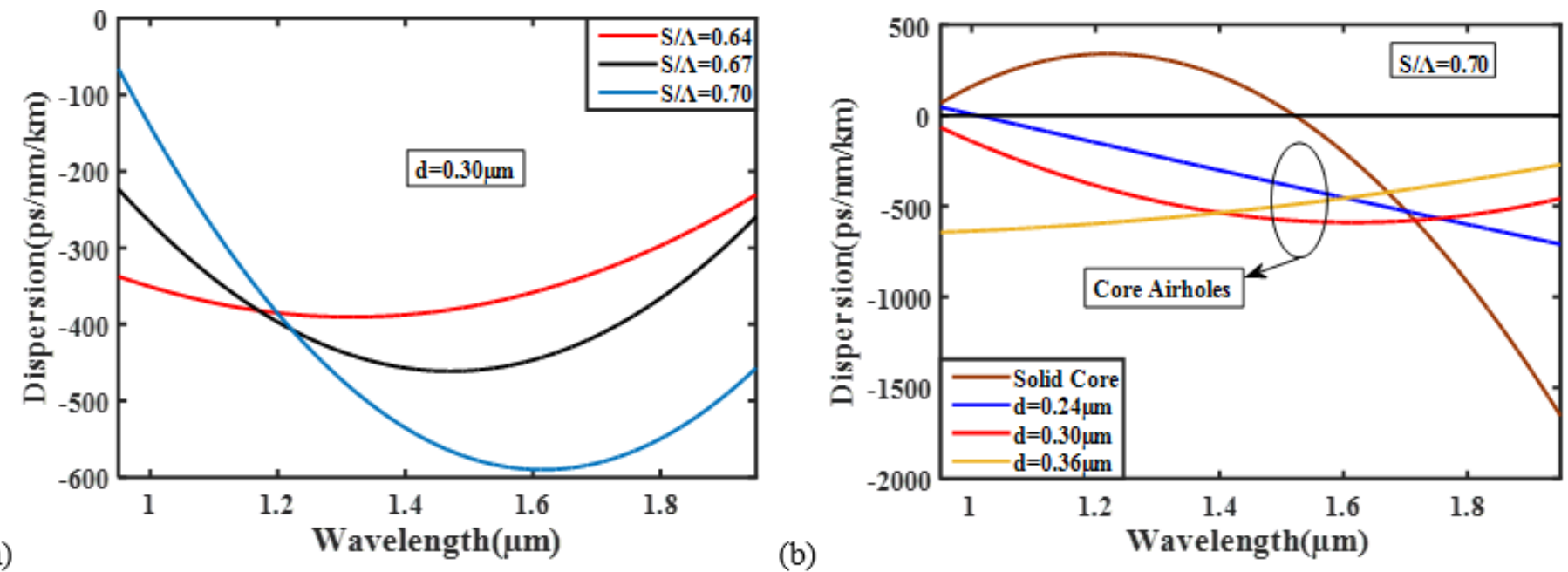

Figure 5

The figure of dispersion deviation with wavelength for the change in (a) HPD ratio and (b) diameter of circular core airhole.
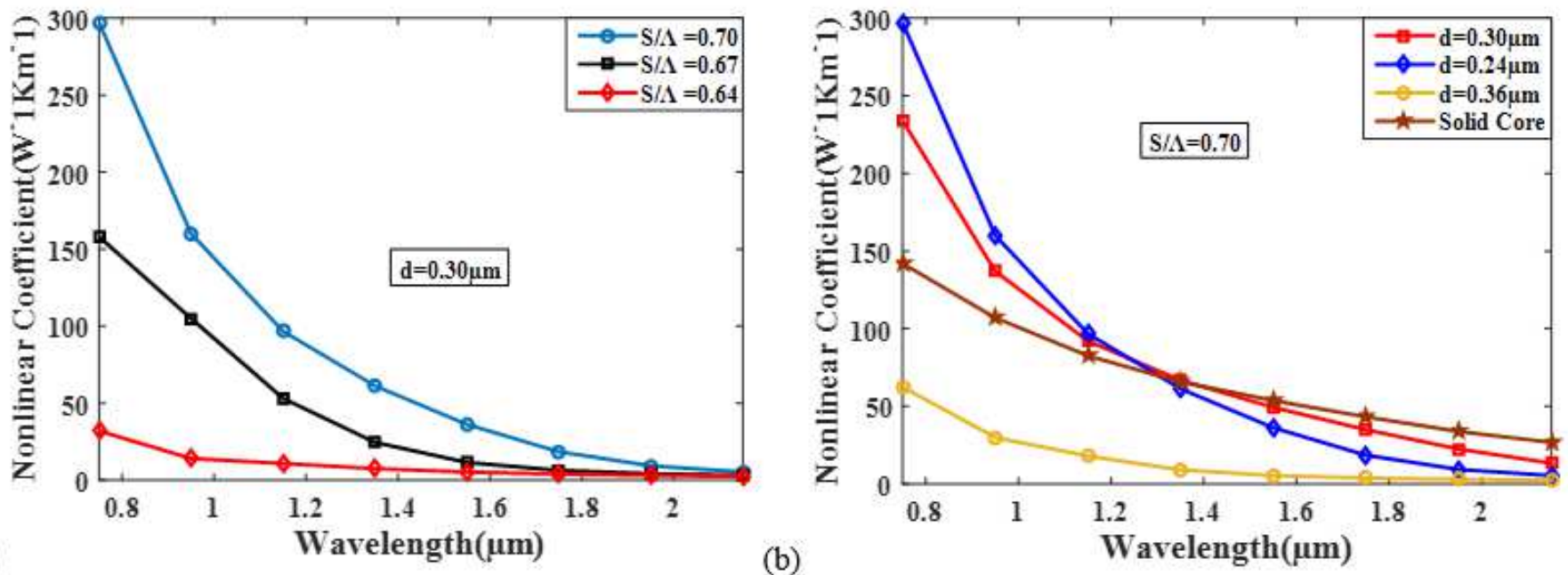

Figure 6

Variation in nonlinearity values with change in operating wavelength for the divergent values of (a) HPD ratio and (b) circular core airhole diameter. 

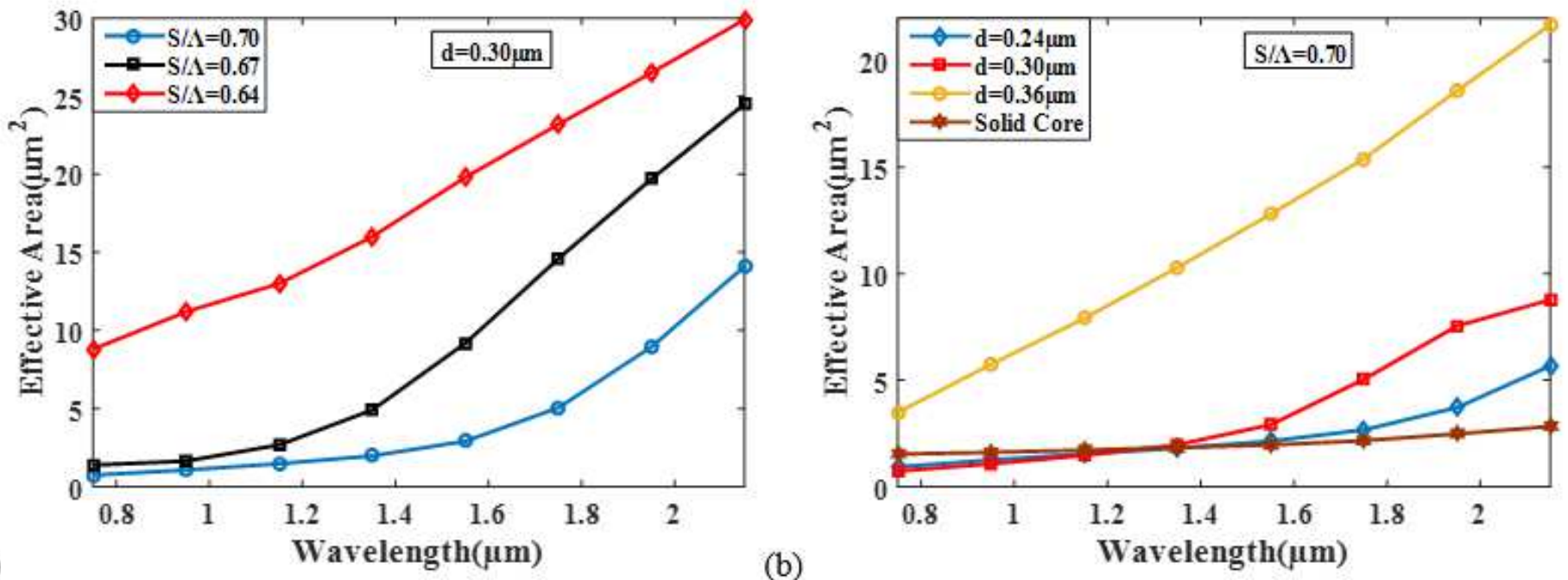

Figure 7

The graph of effective area variation with wavelength for the change in (a) HPD ratio and (b) diameter of circular core airhole.

(a)

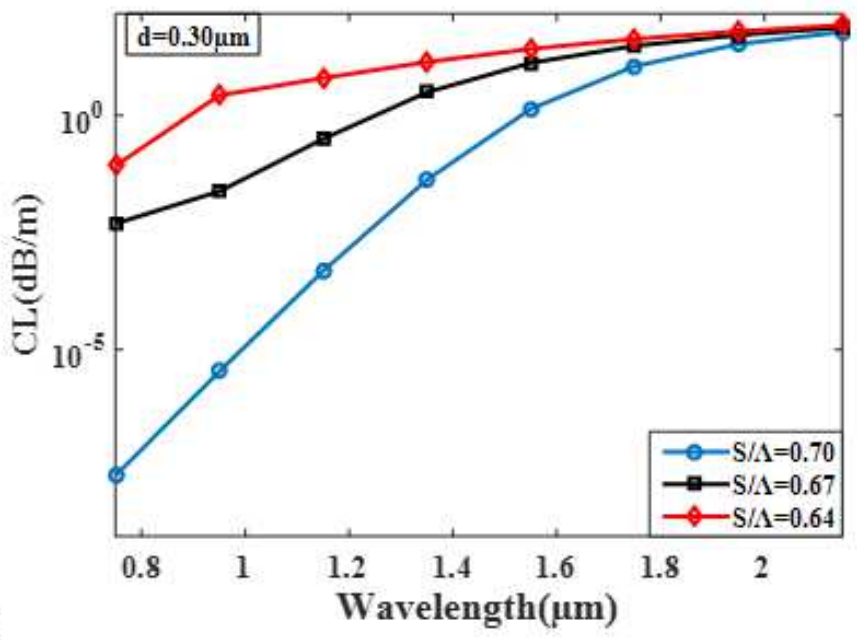

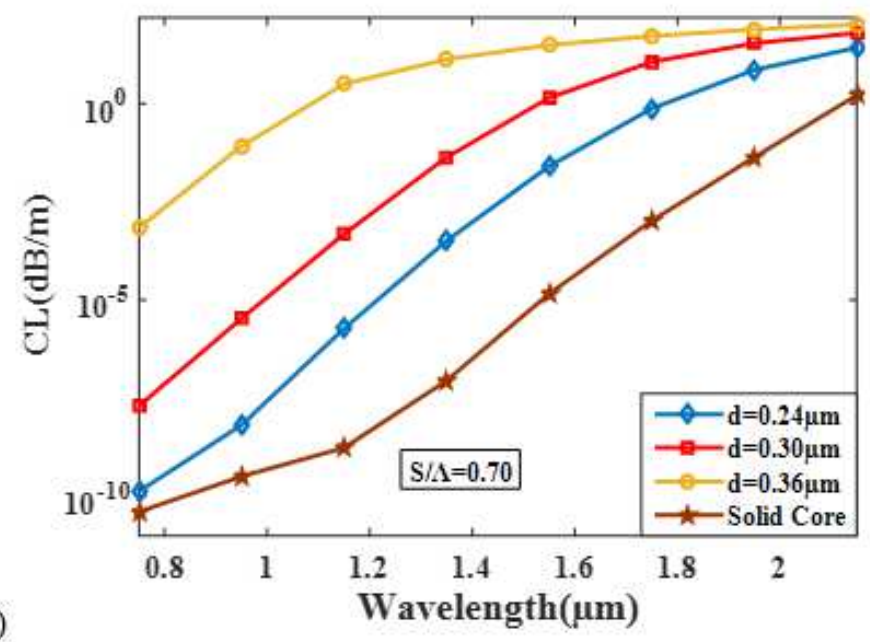

(b)

Figure 8

Change in confinement loss $(\mathrm{CL})$ with operating wavelength for the different values of (a) HPD ratio and (b) circular core airhole diameter. 

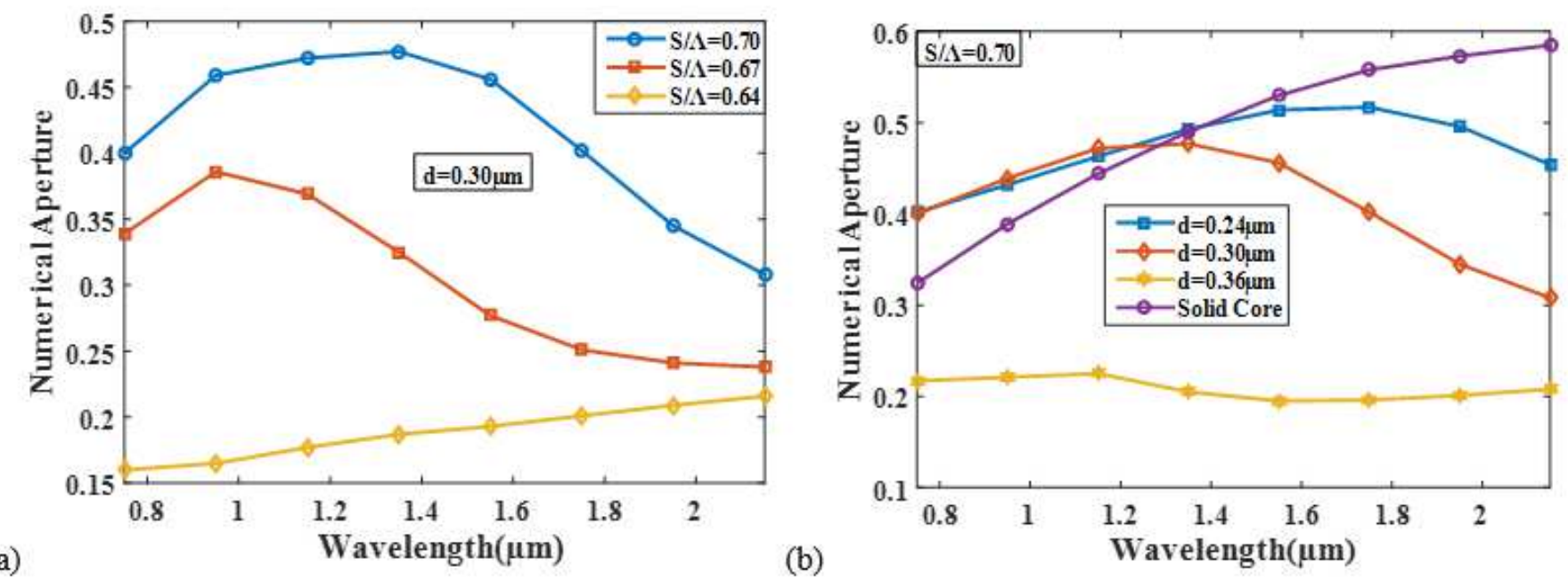

Figure 9

Variation in numerical aperture (NA) values with change in operating wavelength for the divergent values of (a) HPD ratio and (b) circular core airhole diameter.

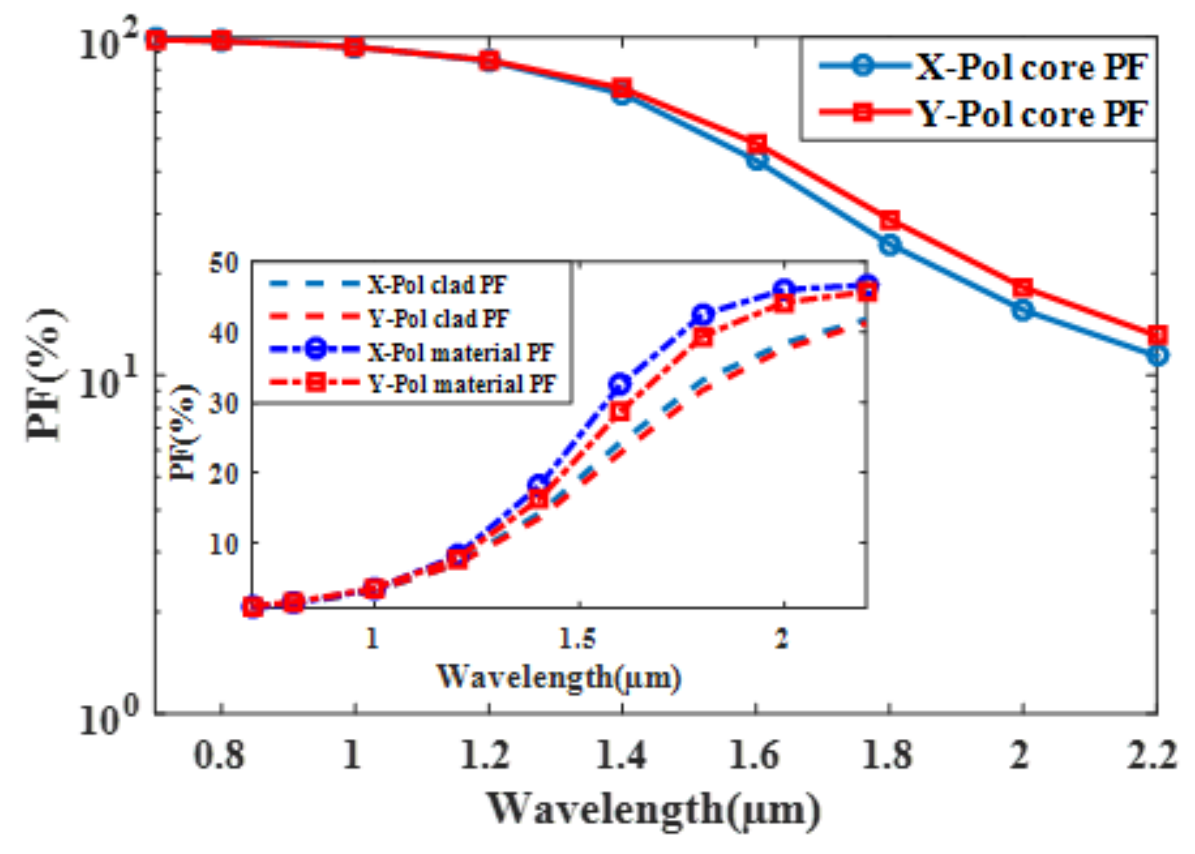

Figure 10

The change in power fraction of the core with variation in operating wavelength for HPD ratio of 0.70 and a circular core airhole diameter of $0.30 \mu \mathrm{m}$. 

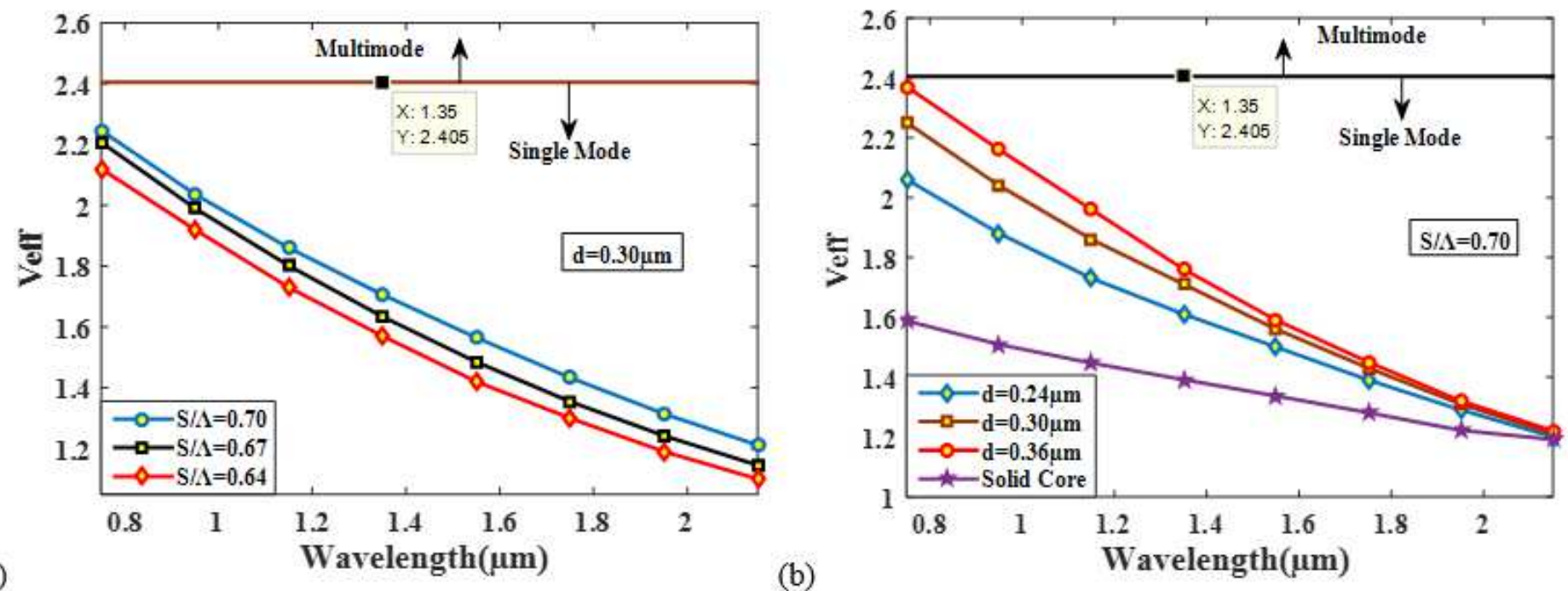

Figure 11

The diversion in Veff with different operating wavelengths for the divergent values of (a) HPD ratio and (b) circular core airhole diameter.

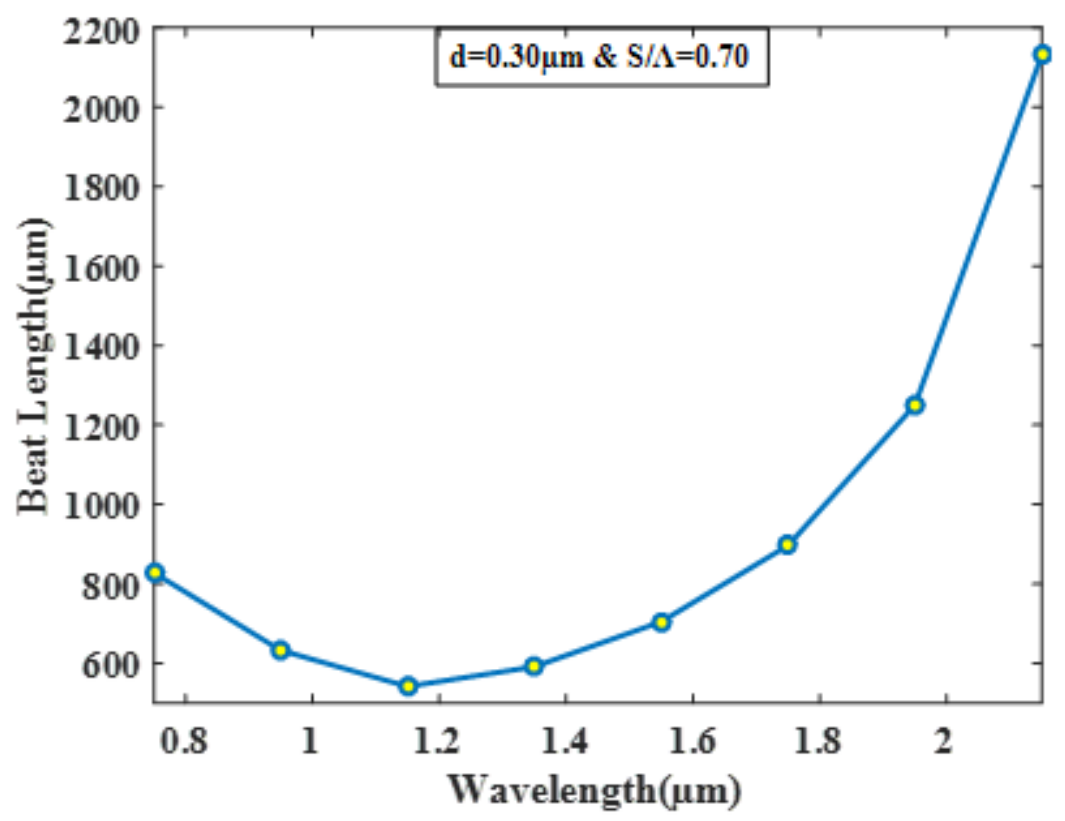

Figure 12

The plot of deviation in beat length for the change in operating wavelength at core hole diameter of $0.30 \mu \mathrm{m}$ and HPD ratio $(S / \Lambda)$ equals to 0.70 . 